\title{
Hospital Ownership Conversions: Defining the Appropriate Public Oversight Role
}

\author{
Frank A. Sloan, Duke University and NBER
}

\section{Executive Summary}

This paper reviews recent empirical evidence on the effects of hospital ownership conversions on quality of care and provision of public goods, such as uncompensated care, and presents new results on these topics based on hospital discharge data from the Healthcare Cost and Utilization Project's (HCUP) Nationwide Inpatient Sample. My analysis of these data reveals that conversion from government or private nonprofit to for-profit ownership has no effect on in-hospital mortality, but rates of pneumonia complications increased following conversion to for-profit status. Other research, discussed in the paper, found increased mortality rates following discharge from the hospital for patients admitted to hospitals that had converted to for-profit ownership. There was no effect of such conversions on the propensity to admit uninsured or Medicaid patients. Clearly, there is considerable heterogeneity in outcomes attributable to conversions. Overall, the evidence suggests a role for public scrutiny of hospital ownership conversions.

\section{Introduction and Policy Context}

The hospital industry attracts much public scrutiny, given its important role in providing personal health services, its size-about 3 percent of gross domestic product, the importance of hospitals as employers in the communities they serve, and the high share of hospital revenue from public sources. During the last two decades, the industry has experienced a dramatic downsizing at the same time, and for that reason, the methods of paying for hospital care have changed. The market for hospital care in the year 2000 was much more competitive than it was in 1980 .

Downsizing has taken various forms. First, there has been a reduction in the number of hospitals. In 1980, there were 5,830 "community" hospitals (nonfederal short-term general hospitals located outside 
institutions). By 1999, the latest year for which data are publicly available, the number had fallen to 4,956 (figure 5.1). The number of community hospitals peaked during the 1970s. Second, existing hospitals have reduced bed capacity from a peak of slightly over 1.0 million beds in 1983 to 830,000 beds in 1999 (figure 5.2). Third, hospitals have diversified, integrating both vertically and horizontally, and they have sought new ownership and management. As an extreme measure, many hospitals have closed.

For-profit $(F)$ hospitals run counter to the national trend in number and bed capacity (figures 5.1 and 5.2). The number of such hospitals has remained relatively constant in terms of numbers of hospitals and has risen in terms of number of beds under such hospital ownership. Although the number of private nonprofit hospitals $(N)$ peaked in 1984, as did the number of beds, the subsequent decline in both has been small relative to the decline in number of public $(G)$ hospitals and beds in such hospitals. In fact, most of the decline in community hospital capacity has occurred in state and local government community hospitals. Thus, the trend has been to a privatized hospital system with some relative increase in the share of private hospitals under for-profit ownership. These changes reflect hospital closings, mergers, as well as ownership changes among existing hospitals.

This study focuses on hospital ownership changes and the effects of such changes. Although government or private nonprofit ownership to for-profit ownership receives the most publicity, in fact, changes have occurred in all directions (Needleman et al. 1997). Relatively more attention has been paid to conversions from $G$ and $N$ to $F$ ownership for several reasons. There is a concern that hospitals with a profit-seeking mission as an explicit motive are less likely to accept unprofitable cases for treatment, such as persons who lack health insurance or who are underinsured. Given the goal of maximizing profit, such hospitals may be more likely to exploit loopholes in the reimbursement rules; they may be more willing to reduce quality of care, especially quality attributes that are difficult for patients, and perhaps even their physicians, to monitor ("noncontractable quality"; see, for example, Hart et al. 1997).

Allegations of adverse effects associated with ownership conversion are easily made. But obtaining rigorous empirical support for such allegations is a much more difficult matter. Any in-depth study of the effects of ownership change on access to and quality of care and on business practices should account for the following factors. 


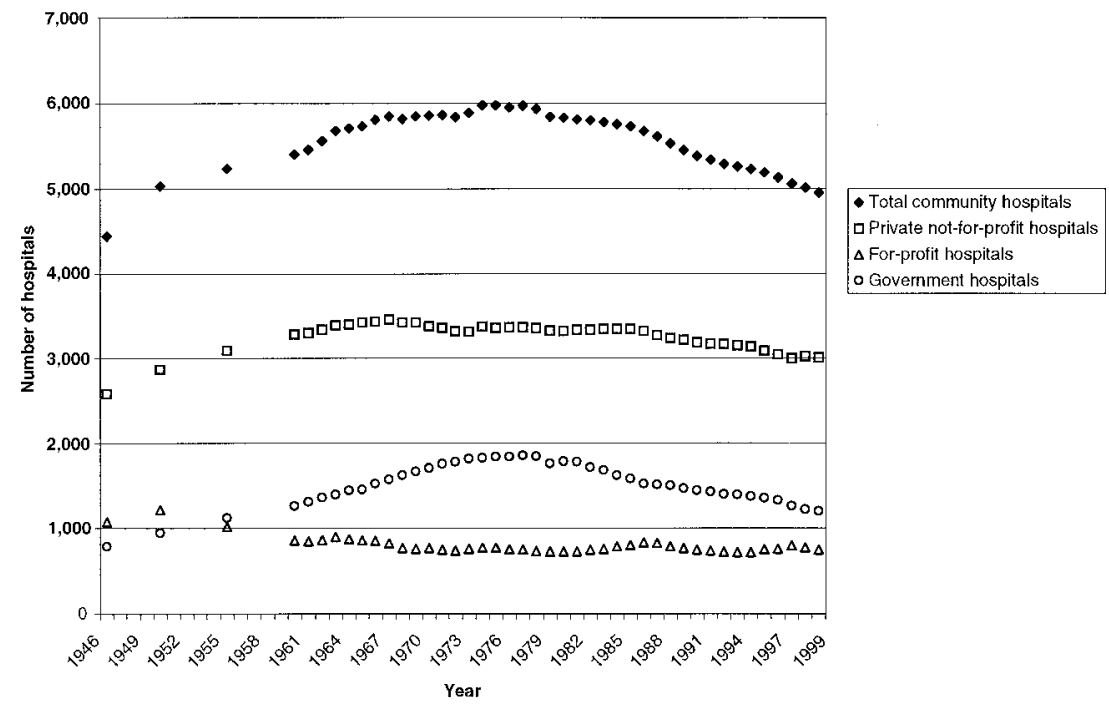

Figure 5.1

Number of hospitals in the United States

Source: American Hospital Association (1976, 1979, 2001). The data before 1979 are for nonfederal, short-term general and other special hospitals, which include community hospitals plus hospitals in institutions.

First, hospitals do not change ownership in a vacuum. Hospitals that convert may have specific attributes that distinguish them from hospitals that do not convert. These attributes may be a characteristic of the hospital and/or of the market in which the hospital operates. If a hospital did not change ownership in the particular way proposed, what was the alternative course of action? The hospital industry is a mature industry, in a sense, more like steel than e-commerce. In an industry that is downsizing, there are rarely many attractive alternatives. Thus, even if the outcomes are worse than before, such outcomes could have been even worse if the choice to change ownership had not been made. The alternative to conversion may have been closure. Under such circumstances, all persons in the locality may have experienced a decrease in access to hospital care, and the loss of jobs to the community may have been far greater than occurred as a consequence of "efficiency measures" implemented by the acquirer. It is essential to ask the "what if" question, both in policy and in empirical analysis of effects of ownership changes.

Second, some of the observed changes reflect change in ownership per se, rather than the effects of change in type of ownership. This is 


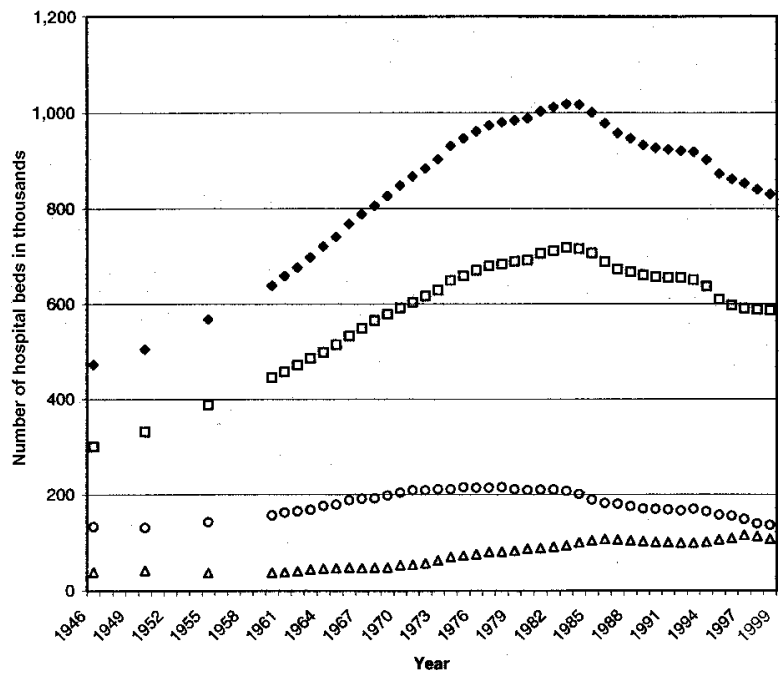

- Total community hospitals 口Private not-for-profit hospitals $\triangle$ For-prolit hospitals o Government hospitals

Figure 5.2

Number of hospital beds in the United States

Source: American Hospital Association $(1976,1979,2001)$. The data before 1979 are for nonfederal, short-term general and other special hospitals, which include community

particularly true during the first few years following a conversion, as hospitals adjust to new management and strategies.

A third point pertains to policy adoption based on empirical evidence of undesirable outcomes following specific types of hospital ownership conversions. If changes in mission and in behavior are observed, are there more direct and efficient policy instruments for ensuring desirable behavior than simply blocking a certain type of conversion? For example, if fraud and abuse in hospital reporting of patient information for purposes of reimbursement is a widespread practice, a more direct approach would involve direct public oversight and enforcement rather than indirectly affecting such behavior by influencing the mix of hospitals according to their propensities to engage in undesirable behaviors. As discussed below, some researchers have found that profit-seeking behavior is contagious. That is, when for-profit hospitals engage in certain kinds of behavior, their hospital competitors with different ownership forms may emulate it.

There is a lot of empirical literature on the relationship between hospital ownership and various performance measures (see, for example, Sloan 2000). In general, the literature reveals that private hospitals, 
whether they are for-profit or nonprofit, are more alike than different. The vast number of studies, however, have assessed the effects of ownership type on hospital behavior rather than ownership conversions. The latter may be particularly insightful because they discuss location and characteristics that potentially influence behavior associated with location constant and examine changes that occurred post- versus preconversion. Norton and Staiger (1994) found differences in hospital behavior by ownership status, but the differences were attributable to where for-profit versus other types of hospitals decided to locate. For example, a profit-seeking hospital may decide to locate in a relatively affluent suburb, where well-insured persons are located, rather than in an inner city, where people are much more likely to be uninsured or to be enrolled in Medicaid (one of the less generous third-party payers).

The dearth of studies on hospital ownership conversions reflects the difficulty of obtaining accurate data on conversion dates and conversion types. This problem has been remedied in the present study and in some studies reviewed below. After comparing ownership codes from two independent sources, the Annual Survey of Hospitals (conducted by the American Hospital Association) and Medicare Cost Reports, my students called hospitals for which the two sources differed to determine whether the conversion occurred, when it occurred, and the ownership types before and after conversions. In total, about 300 telephone calls were made.

Compared to the number of quantitative studies, there have been very few qualitative studies of ownership and ownership conversions. Qualitative studies may be called "soft" but at the same time, they can reveal differences among and changes in decision-making processes that otherwise can only be inferred very indirectly from outcome changes. By peering inside hospital decision making, especially decision making in the presence of major stress and organizational change, we can enhance our understanding of these changes. Such analysis also provides an important cross-check on findings from the quantitative analysis.

Qualitative analysis is not done mostly because it is so difficult to do. Decision makers undergoing change and/or associated with choices that did not lead to a successful outcome are not likely to want to have their decisions and the consequences scrutinized. Also, there is no explicit hypothesis testing, as in quantitative research. In the end, one gains an impression without the sharply defined results of a rejected null hypothesis. 
In this paper, I review and evaluate very recent research (mostly published in 2000 or later) on the relationship between hospital ownership and behavior, and I present new empirical results on ownership conversions based on empirical analysis of hospital discharge data for the years 1988 through 1996, the Healthcare Cost and Utilization Project's (HCUP) Nationwide Inpatient Sample (NIS). HCUP is an intramural program of the U.S. Agency for Healthcare Research and Quality.

Using qualitative as well as quantitative evidence, the public policy questions addressed in this paper are those posed above. Does ownership conversion, especially to the for-profit ownership form, lead to increased care barriers, diminished quality of care, and profit-seeking billing practices designed to maximize reimbursement? Do acquirers of hospitals pay prices for the facilities that are commensurate with earning a fair rate of return on their investments? Or do acquirers pay too little for community assets in the form of hospitals? If there is evidence of market failure in this context, what are the appropriate public remedies?

Section II of this paper reviews empirical evidence on the effects of ownership and ownership conversions on behavior. Section III describes a new investigation of the effects of ownership conversions from $G$ and $N$ to $F$ ownership and the reverse, from $F$ to $G$ or $N$. To the extent that hospital decision making becomes more profit-oriented when hospitals convert from $G$ or $N$ status, one should observe the opposite when hospitals convert from $F$ to $G$ or $N$ status. Thus, by examining the effects of conversions in both directions-toward and away from for-profit status- the empirical analysis makes it possible to distinguish the effects of change of ownership type from the effects of conversion per se. Section IV presents results from a sample of Medicare beneficiaries and Section $\mathrm{V}$ results from a sample of patients not yet age-eligible for Medicare. Section VI further evaluates the findings and explores the implications of the results for public policies as they relate to hospital ownership conversions.

\section{New Empirical Evidence on Ownership Effects and on Hospital Conversions}

\section{Why Hospitals Convert}

Using qualitative as well as quantitative methods, several recent studies have analyzed why hospitals change ownership status. The major 
determinants of ownership change are financial distress prior to the change, mostly due to a reduction in aggregate demand for hospital inpatient care and an increase in competition among hospitals, which necessitates implementation of new competitive strategies that were more difficult to introduce under the prior regime. A study of five public hospitals that converted from public to nonprofit ownership gave two reasons for the changes: (1) a reluctance of public facilities to expand beyond their political jurisdiction and (2) governance and management restrictions that made it more difficult to compete with other hospitals (Legnini et al. 2000).

Burns et al. (2001) performed case studies of sixteen hospitals that changed ownership between 1993 and 1996. Among the sixteen hospitals were conversions from private nonprofit to for-profit, for-profit to nonprofit, public to for-profit, and public to nonprofit ownership. The case studies revealed two primary motivations for conversion regardless of ownership type, even though the two both come down to money. First, with one exception, the hospitals reported current or anticipated financial stress as a motivation. By joining a chain or reducing managerial constraints in the case of public hospitals, the hospitals hoped to improve financial performance. A motivator for the hospitals converting from nonprofit to for-profit governance was access to equity capital. In one case, the hospital was not considered to be "strategic enough" to justify further investment by its nonprofit owner, but the hospital fit the strategy of a for-profit purchaser. In the case of for-profit to nonprofit conversions, the hospital had not met the former owners' required financial return. Reasons for the public to private conversions included poor hospital financial management under the previous ownership. In the extreme, the alternative for the hospital was closure.

Second, nearly all the hospitals said that they were faced with an inability to compete for managed-care contracts. By joining a larger, more dominant hospital in the local market, the hospital was in a stronger position when dealing with managed-care organizations. A desire to change its mission was a motive only rarely for an ownership conversion. Transitions to for-profit ownership were motivated by both "pull" and "push" factors. The former included an attractive financial offer; the latter included siphoning off hospital cash flow by the former owner. Transitions from for-profit ownership to the other forms tended to be motivated by push factors, including failure to realize a required return.

In a review of conversion financing, Robinson (2000) reported that most conversions from private nonprofit to for-profit status are 
initiated by the nonprofit trustees and thus resemble friendly leveraged buyouts. At the same time, many nonprofit hospitals have created for-profit subsidiaries and continue to function as nonprofit organizations.

Conover et al. (2001) provide a recent study of the determinants of hospital closings, mergers, and ownership changes. Hospitals that converted experienced on average a major decline in financial performance in the years immediately preceding conversion. In this sense, converting hospitals were not typically successful businesses prior to conversion. In the absence of a change in ownership, some other outcome, including closing, was often inevitable.

\section{What Is Being Bought and Sold?}

The financial transaction involves a purchase or lease price, and much more. The transaction may be parsed into two elements, the price and provisions of the transaction other than price. ${ }^{1}$ On price, the issue is whether or not acquirers pay a fair price for the facility, given discounted cash flows that are likely to accrue from the transaction. In the vast majority of transactions in the general economy, the underlying assumption is that buyers and sellers are sufficiently informed to allow the market to set the transaction price. In this context, there is a concern that sellers may not be sufficiently well informed and may obtain too little in return for relinquishing a major community asset. On the nonprice dimensions, there is a concern that acquirers will be driven by profit considerations, and provision of public goods by hospitals, such as provision of care to uninsured persons, public health programs, and education and research other than that sponsored by an outside public or private organization, will be reduced as a consequence.

Much of the evidence on these two questions comes from case studies of ownership conversions. To date, the literature has provided no clear answers to the price question. As far as the nonprice question is concerned, the evidence is somewhat reassuring but preliminary.

The price question has been addressed by two recent empirical studies. Conover and Sloan (2001) assessed rates of return on a sample of hospital purchases starting in the early 1980s. Wide variations in rates of returns were observed, with conversions to for-profit status exhibiting higher rates of return than other types of changes in hospital ownership. On average, rates of return were well above the cost of capital when hospitals converted to for-profit status, but somewhat closer to the cost of capital otherwise. 
In an earlier study, rates of return tended to be closer to the cost of capital, but that study was limited to ownership conversions that occurred in North and South Carolina and had a shorter postconversion follow-up period, meaning that more of the measured return was based on projected rather than actual cash flows (Sloan et al. 2000). Methodologies used in the two studies were similar. A weakness of both studies is that it was possible to make only crude adjustments for nonprice concessions granted by buyers to sellers.

On the second question, it is necessary to glean bits of evidence from qualitative studies. Blumenthal and Weissman (2000) provided case studies of the sales of three teaching hospitals to investor-owned hospital chains, focusing in particular on the effects of the sales on the organizations' medical education missions. In all three, there were no adverse effects. The authors attributed the lack of an effect to three factors. First, the for-profit purchasers considered preservation of some unprofitable activities a cost of doing business at these institutions. The contracts of sale stipulated that specific resources be devoted to teaching, resource, and charity care. Second, private subsidization of medical education may not be that burdensome to the new owners, given external subsidies such as for graduate medical education. Third, at the time the study was written, all three institutions were doing well financially. If faced with financial stress, their missions could change.

Cutler and Horwitz (2000) studied conversions of the Wesley Medical Center in Wichita, Kansas, and HealthOne in Denver, Colorado. Both were large teaching facilities. The first was purchased by Hospital Corporation of America in 1985. Two foundations were funded with proceeds from the sale. In the HealthOne transaction, the hospital entered into a joint venture with Columbia/HCA in 1995. After the transaction, the new HealthOne organization concentrated on graduate medical education, paying faculty and residents and administering medical education at its facilities. Cutler and Horwitz found improvements in financial performance after the conversion and the mission previous to ownership conversion was maintained. Improved financial performance came in part from the skill of the for-profits at increasing public sector reimbursements, not solely from efficiency gains.

Outcomes following conversion are not uniformly favorable. Burns et al. (2000) described "the Allegheny system debacle." This is a case study involving the Allegheny Health, Education and Research Foundation, which consisted of a major teaching facility in western Pennsylvania and several affiliate hospitals throughout the state. The authors 
attributed failure in part to failure of external oversight mechanisms, including lack of performance of the organization's board, accountants, and auditors; bond-rating agencies; and state government. There was ambiguity regarding the powers of the state attorney general, state politics, and jurisdictional issues with federal bankruptcy court. Pennsylvania law is ambiguous regarding the attorney general's power over transactions with nonprofits.

The sixteen case studies reported in Burns et al. (2001) revealed that, in all but one conversion, the financial status of the hospital improved after the conversion. There were funds from the sale or lease of the facility. New hospital owners invested in hospital plant and equipment, particularly in hospitals converting from private nonprofit to for-profit status, although in some cases, the investment after the conversion was not as great as hospital management had anticipated. Improvements in margins were achieved by cutting staff, ${ }^{2}$ improving purchasing practices, and consolidating services lines in a network approach.

Changes in decision-making style depended mostly on whether the new organization was a multihospital system or a freestanding facility. In fact, the transition to being part of a larger system was on balance more important than was the specific change in ownership form. Those hospitals that became part of a chain lost some local autonomy in decision making. But there were differences in the strategic decisionmaking process among chains and even in treatment of individual facilities within a particular chain. Overall, the organization's general mission remained intact, as specified, for example, in the sales contract, while the methods for achieving its objectives changed.

Anderson et al. (2001) studied changes in internal decision making after conversion in ownership status at the same set of converting hospitals as in Burns et al. (2001), but they also included a comparison with twenty-two nonconverting hospitals matched on location, ownership (prior to conversion), and bed size. They found that, relative to nonconverted hospitals, converted hospitals had greater levels of physician and nurse participation in hospital decision making; in the converted group, these health professionals had greater influence over final choices made. These agents' interconnections and interactions may have intensified as the organizations tried to cope with the changes brought about by the conversion. Alternatively, granting more influence to professionals may have been a compromise struck to overcome professionals' resistance to change. The study assessed participation at three to six years following ownership conversion. 
Thus, the change in participation was not only transitory. However, increased participation by health professionals is more closely related logically to provision of care to individual patients than to policies affecting the community as a whole, such as provision of care to the uninsured.

\section{Effects of Hospital Ownership Changes on Quality of Care}

Two recent studies have assessed differences in quality of care by hospital ownership status. One is a comparison of differences in quality by ownership. The other explicitly examined the effect of change in ownership on quality of care. Both studies relied on Medicare administrative records to gauge outcomes of care. At least to some extent, both studies account for methodological complexities of discerning effects of conversions discussed in the previous section. Both studies imply that conversion to for-profit status may lead to some reduction in quality of care as measured by mortality rates at various times after discharge from the hospital.

McClellan and Staiger (2000) examined all Medicare hospital discharges for acute myocardial infarction for 1984-1994 and for ischemic heart disease for 1984-1991. The outcome measures were death within ninety days of admission and cardiac complications leading to readmission. Many of the details are beyond the scope of this review. One purpose of that study was to develop a hospital-specific measure of quality with a high signal-to-noise ratio. However, the findings on hospital quality, measured in terms of patient survival, are highly pertinent here.

First, when county-level fixed effects were included, the estimated mortality difference between $N$ and $F$ hospitals fell by roughly half, implying that for-profit hospitals tend to locate in geographic areas where hospital quality is not as high in general. This may be partly because for-profits often acquire facilities that are not doing well financially. This still left some amount of lower quality attributable to being a for-profit hospital.

Second, in the three markets they considered in detail, for-profit hospitals did not have higher mortality rates. In one of these markets, a for-profit firm acquired a low-quality hospital, gauged in terms of mortality rates, and quality at that hospital subsequently improved.

Overall, these results lend support to the conclusion that some of the results on quality differences reflect differential patterns by hospital 
ownership in the location of their facilities rather than in fundamental differences in hospital behavior. The authors concluded that:

[O]n average, the performance of not-for-profit hospitals in treating elderly patients with heart disease appears to be slightly better than that of for-profit hospitals, even after accounting for systematic differences in hospital size, teaching status, urbanization, and patient demographic characteristics. This average difference appears to be increasing over time. However, this small average difference masks an enormous amount of variation in hospital quality within the for-profit and the private nonprofit categories. Our case-study results also suggest that for-profits may provide the impetus for quality improvements where, for various reasons, relatively poor quality of care is the norm. (p. 111)

In a comment on the McClellan-Staiger study, Wolfram (2000) stressed that survival to ninety days after the admission date represents only one dimension of quality. While no informed person would seek admission at a hospital with a markedly higher mortality rate, other attributes such as the time that providers spend with patients, are also plausibly important. She also noted that McClellan and Staiger may not have adequately controlled for patient selection. For example, if more severely ill patients (in ways that the researcher cannot measure) seek care at private nonprofit hospitals, the true differential in quality between these institutions and for-profits will be higher than the difference the researchers measured.

Several strategies deal with this issue, none of which is perfect. One is to include more explanatory variables, such as Wolfram's suggestion to include a binary variable for the presence of a trauma center. ${ }^{3}$ If private nonprofits are more likely to have trauma centers, they may attract the most vulnerable heart attack victims. ${ }^{4}$ Other approaches involve instrumental variables and difference-in-difference. In the end, more progress is likely to be made by supplementing statistical approaches with case studies that identify changes in processes of care that occur in hospitals with different ownership form.

Picone et al. (forthcoming) also assessed health outcomes using Medicare data for the years 1984-1995. They studied death at thirty days, six months, and one year. The underlying hypothesis was that hospitals converting to for-profit ownership raise profitability after acquiring the facilities in part by reducing dimensions of quality not readily observed by patients or their physician agents and by raising prices. Hospital-specific mortality rates after discharge from the hospital are one important dimension of such hard-to-observe quality. The authors found that one to two years subsequent to conversion to 
for-profit status, the mortality rate of patients at one year following admission rose markedly. At the same time, hospital staffing decreased. A similar decline in quality was not observed after hospitals switched from for-profit status to government or to private nonprofit ownership status. At three or more years following conversion to for-profit ownership, the decline in quality was much lower (relative to the quality that prevailed at the hospital at five years before the conversion occurred). A plausible interpretation consistent with the data is that the new for-profit owners (or their managers) experienced adverse effects after the staffing cuts and reversed course at three years or so following the date of acquisition. By adding staff, some improvements in quality were then realized.

\section{Effects of Hospital Ownership Changes on Provision of Public Goods}

A major policy concern is that ownership conversions, especially to the for-profit form, will result in decreased provision of public goods. Most frequently mentioned among such public goods is provision of care to the uninsured, sometimes cast in terms of provision of uncompensated care. The empirical evidence on this score is mixed. Comparing provision of uncompensated care across ownership types, one is struck by the similarity between shares of dollar amounts of uncompensated care relative to hospital revenue provided by $N$ and $F$ hospitals. Government hospital uncompensated shares, not surprisingly, tend to be higher than for $N$ and $F$ hospitals (Sloan 2000).

A recent study, which focused on ownership conversions, calls the conclusion that the main distinction in provision of uncompensated care is between private and public hospitals into question. Using unpublished and confidential data on revenue from the American Hospital Association, Thorpe et al. (2000) studied the effects of conversion from $N$ to $F$ status on hospital provision of uncompensated care. They measured uncompensated care as bad debt and charity care charges deflated by each hospital's cost-to-charge ratio for 1991-1997. To account for variations in hospital capacity and inflation, they divided this amount by total expenses for the hospital. They included several explanatory variables in their analysis, most notably hospital fixed effects. They found little effect of conversion to for-profit status on Medicaid patient loads. However, uncompensated care fell after conversion from $N$ to $F$ status, falling from 5.3 percent to 4.7 percent of hospital revenue on average. The 0.6 percentage-point reduction in 
uncompensated care amounted to about $\$ 400,000$ less being spent per converted hospital on uncompensated care. For public hospitals converting to for-profit status, the decrease was greater, from 5.2 to 2.7 percent, or $\$ 800,000$, per hospital. The authors expressed the amounts in terms of admissions lost even though they provided no indication whether the decrease occurred on the inpatient or outpatient sides of the hospital or in some combination thereof. Thorpe et al. concluded that:

Of concern, however, is our findings that the provision of uncompensated care is reduced when hospitals convert to for-profit status. Of particular concern is the large reduction in uncompensated care observed among public to for-profit hospital conversions. Because the bulk of these conversions occurred among smaller, rural public hospitals, such conversions could limit access to hospital care among the uninsured.(p. 192)

The implication is that conversions cause reductions in uncompensated care and that these reductions could not be accounted for by inward shifts in demand largely exogenous to the hospitals involved in the conversions. The authors noted that their result for nonprofit to for-profit conversions had not been found in previous studies (see, for example, Desai et al. 2000). I shall return to this issue in the next section when I discuss my own empirical analysis.

Several recent studies have focused not on the effect of ownership change on the provision of public goods and more generally on product mix, but more specifically on the effects of competition from for-profit hospitals on the behavior of nonprofit and public hospitals. ${ }^{5}$ The Disproportionate Share (DSH) Program was implemented nationally to provide a greater financial incentive for hospitals to deliver care to the poor. Subject to this federal law, each state could design its own DSH program.

Duggan (2000a, 2000b) studied the change in financial incentives created by California's variant of the DSH program on the propensity of hospitals to treat Medicaid recipients. This DSH program provided an explicit financial incentive for hospitals to admit Medicaid patients. It increased revenues to hospitals for which low-income patients constituted more than 25 percent of their patients. Hospitals above this threshold experienced a revenue increase, and those below this threshold had an incentive to increase their low-patient shares to this level.

Duggan (2000b) found an appreciable difference in response between public and private hospitals, regardless of whether they were $N$ 
or $F$. The public hospitals faced a "soft budget" constraint; that is, as their revenues from DSH increased, their sponsors lowered their subsidies accordingly. By contrast, both $\mathrm{N}$ - and F-owned facilities could accumulate wealth from this new revenue source. He concluded that the greatest difference in response to the DSH incentive was between public and private rather than between $N$ and $F$ hospitals.

In the second study, Duggan (2000a) found that DSH resulted in a shift of Medicaid patients from public to private hospitals. The magnitude of the shift was directly related to the market share of for-profit hospitals in the county. In particular, the response of $N$ hospitals to the DSH incentive was greater when they faced more competition from the for-profit sector. The implication is that $N$ hospitals behave more like profit-maximizers when faced with the market discipline of the for-profits. Various tests that Duggan performed rejected alternative explanations for his finding (for example, quality of care in the public facilities). An examination of the effects of competition from $F$ hospitals on the board composition of $N$ hospitals revealed that $N$ hospital boards had larger shares of physicians when they faced competition from the $F$ hospitals. Duggan reported that $F$ boards contained large numbers of physician members. ${ }^{6}$ In this sense, $N$ boards in F-influenced areas may put physicians on the boards as their mission becomes more profit oriented. However, other interpretations seem at least as likely. For one, placing physicians on the board may be a competitive response by $N$ hospitals to retain their medical staffs.

Silverman and Skinner (2001) assessed the effects of hospital competition on mission, but from a different perspective. Since implementation of the Medicare Prospective Payment System (PPS), hospitals have known that the pattern of reporting of diagnoses and procedures can affect the diagnosis-related group (DRG) assigned to the case and hence the amount of revenue received from Medicare. Upcoding involves rearranging reports of diagnoses and/or procedures, with the result that the patient falls within a higher-priced DRG. Some upcoding may be perfectly legitimate. In some cases, it may improve accuracy of reporting. But given the financial incentive to upcode, there is a large gray area. More profit-oriented hospitals may be more willing to take advantage of the incentive to increase revenue from Medicare. Even for those hospitals that are not fully profit oriented, pressures from competition may force them to act in this way. The authors limited their analysis to hospital admissions involving pneumonia and respiratory infections. Between 1989 and 1996, the number of the most 
expensive DRG in this diagnosis family rose by 10 percentage points among stable $N$ hospitals, 23 percent among stable $F$ hospitals, but 37 percentage points among $N$ hospitals that converted to $F$ status.

Silverman and Skinner obtained two major findings. First, holding many other factors constant, for-profit hospitals were more likely to upcode in this diagnostic category than most nonprofit and government hospitals. Second, the authors found evidence that upcoding among $N$ hospitals was much more likely when they faced greater competition from $F$ hospitals. By contrast, the upcoding behavior of the for-profits was not affected by the presence of nonprofits. ${ }^{7}$ During the latter part of the 1990s, Medicare became more aggressive in monitoring hospital billing practices, with the consequence that some hospitals made large payments to compensate for shortcomings in past billing practices. ${ }^{8}$

\section{Evidence from a National Sample of Hospital Discharges}

\section{Objectives of the Analysis}

To assess further the effect of hospital ownership conversions on quality, patient mix, especially willingness to treat publicly insured and uninsured persons, and upcoding, I assessed hospital discharge data from the Healthcare Cost and Utilization Project (HCUP) Nationwide Inpatient Sample (NIS). Results from this analysis are reported in this study for the first time. This data set offers many advantages. There is a very large number of observations, and the data come from many states and are available for several years. The hospital, but of course, not a patient identifier, is provided. The main disadvantage of the data is that no information is available on patients after they were discharged from the hospital. Also, there is no information on hospital outpatient care.

\section{Data and Methods}

The NIS is a compilation of data from state hospital discharge datacollection systems made available through the U.S. Agency for Healthcare Research and Quality. I limited the analysis to hospital admissions occurring during the years 1988-1996. Data from the following states were included for some or all of the observational period: Arizona, California, Colorado, Connecticut, Florida, Hawaii, Illinois, Iowa, Kansas, 
Maryland, Massachusetts, Missouri, New Jersey, New York, Oregon, Pennsylvania, South Carolina, Tennessee, Utah, Washington, and Wisconsin. Each year, the NIS provides discharge abstract data from about 5 to 7.1 hospital stays from over 900 hospitals per year. The NIS is designed to approximate a 20-percent sample of U.S. community hospitals. The NIS is not designed to be representative of community hospitals in terms of ownership. Of the states included in the NIS, California and Florida had the most admissions, by far, to for-profit hospitals. Tennessee has a high for-profit market share but is a much smaller state and was included in the NIS only for part of the observational period. Texas, another state with a high for-profit market share, was not included in the NIS.

Separate analyses were conducted on admissions of (1) persons over the age of 65 at admission-hereafter called the "Medicare sample" and (2) births and admissions of persons who were between the ages of 1 and 64 on the admission date-the non-Medicare sample (although a minority of persons in the under-age- 65 group also had Medicare as the primary payer). For the Medicare analysis, the sample was limited to persons who were admitted for one of five primary diagnoses: stroke, hip fracture, coronary heart disease, congestive heart failure, and pneumonia. To facilitate analysis, the NIS 10 percent sample was used with one exception. In the analysis of discharges of persons who were between the ages of 1 and 64 on the admission date, I used a 25 percent sample of NIS's 10 percent patient sample.

The Medicare and non-Medicare samples were each divided into two subsamples. The first consisted of admissions to hospitals that were under government or private nonprofit ownership prior to conversion and changed to for-profit ownership or remained under government or private nonprofit ownership during the observational period, 1988-1996 (the GN sample). The second included admissions to hospitals that were under for-profit ownership but converted to GN status during the observational period, as well as those that remained for-profit (the $F$ sample).

Six hypotheses about effects of ownership conversions from GN to $F$ and $F$ to GN status were tested. Conversions from $F$ to GN ownership were hypothesized to have the opposite effect of conversions from $G N$ to $F$. By employing a two-sided test, I was able to distinguish between the effects of conversion and those attributable to a change in ownership. In combining the $G$ and $N$ categories, I focused on changes in be- 
havior to and from the for-profit ownership form rather than on the private versus public ownership distinction. The six hypotheses are listed below:

1. Quality of care falls following conversion from $G N$ to $F$ ownership. This may occur because profit-seeking hospitals seek to achieve higher profitability by cutting hospital inputs, such as personnel

2. Quality may be increased, but only when it is profitable to do so, that is, when higher quality results in an additional payment sufficient to cover the additional marginal cost of the higher quality level.

3. Following conversion from $G N$ to $F$ status (when subject to a fixed payment per case, as under the Medicare Prospective Payment System), the hospital becomes more aggressive in reducing length of stay. Again, the motive for reducing stays is to increase profitability.

4. Increasing transfers to nursing homes postdischarge is one manifestation of a strategy for reducing the length of stay.

5. To increase payment from Medicare, the hospital upcodes diagnoses more frequently following a conversion from $G N$ to $F$ status. This is an extension of Silverman and Skinner's (2001) research, but for a different set of diagnoses.

6. Following conversion from GN to $F$ ownership, the hospital becomes less likely to admit publicly insured and uninsured patients. This analysis used only the non-Medicare sample and sought to replicate the finding by Thorpe et al. (2000) that conversion to for-profit ownership led to reductions in hospital provision of uncompensated care.

For the analysis of the admissions of persons aged 65 and over, the dependent variables were inpatient mortality; extended length of stay; length of stay; pneumonia complication; destination at dischargehome (omitted reference group), nursing home, other hospital, or death; and upcoding of diagnoses. Extended length of stay was defined as a stay two standard deviations above the mean stay for the primary diagnosis and the year in which the admission occurred. The pneumonia complication was taken from the list of secondary diagnoses provided on the hospital discharge abstract. In this analysis, elderly persons admitted with a primary diagnosis of pneumonia were excluded.

Upcoding was tested by two analyses. In the first, the dependent variable was 1 if the primary diagnosis was listed as a transient 
ischemic attack (TIA) and 0 if the primary diagnosis was listed as a stroke. Medicare pays more for strokes than TIAs. There is some discretion in classifying patients between these two diagnoses. The second was the DRG weight assigned to the case, limiting the sample to the five primary diagnoses listed above.

A sample of births was analyzed to test the sixth and second hypotheses. The dependent variables were patient did not have private insurance, patient stayed in the hospital for less than two days, and patient had a vaginal birth as opposed to a cesarean section-the underlying presumption being that $\mathrm{C}$-sections are more profitable on average than are vaginal births. With the sample of births, the dependent variable was payment source other than private insurance versus private insurance. The other category included Medicaid, Medicare or other government insurance (such as Veterans Administration, Champus), self-pay or no charge (suggesting no health insurance coverage), and private insurance (the omitted reference group). With the sample of persons with any diagnosis or principal procedure who were between the ages of 1 and 64 at the admission date, the dependent variables were each of the payer categories for public payers and self-pay/no charge with privately insured individuals, the omitted reference group.

With the exceptions noted below, four alternative specifications were employed. The methodology for the Medicare analysis is explained in detail here. Specifications for the non-Medicare were similar. Each successive specification added a set of explanatory variables, retaining the explanatory variables from the previous specification.

The first specification included explanatory variables identifying admissions after ownership conversion occurred, patient characteristics, market characteristics, and binary variables for the year of admission. The patient characteristics were age; race; gender; source of admission-emergency room, nursing home, other hospital versus home; binary variables for the five primary diagnoses; DRG weight; and the DxCG score. The DxCG is a case mix measure that accounts for the patient's secondary diagnoses (see www.dxcg.com).

The market characteristics were a Herfindahl index based on bed shares, the fraction of the population enrolled in health maintenance organizations, population density (population per square mile), hospital beds per 1,000 population, and per-capita income. For hospitals located in standard metropolitan statistical areas (SMSAs), the market area was assumed to be the SMSA. For hospitals located outside SMSAs, the market area was the county. 
In the second specification, I added a conversion fixed effect binary variable. The conversion fixed effects identified admissions to hospitals involved in a conversion from $G$ or $N$ to $F$, or $F$ to $G$ or $N$ during the observational period. In the third specification, I added explanatory variables for hospital characteristics: bedsize; the number of resident physicians per bed, a measure of commitment to medical education; the hospital's operating margin; debt-to-asset ratio; and occupancy rate-all defined for the year in which the admission occurred. For hospitals with a negative operating margin, the operating margin was set equal to 0 and an additional binary variable, "no profit," was set to 1 . Likewise, if the debt-to-asset ratio exceeded 1, the ratio was set to 1 and a binary variable was included to identify such cases. Although the hospital characteristics are possibly endogenous, there is an argument for including them. In their absence, the ownership and ownership change variables may represent other hospital characteristics, including financial distress that may be the true causal determinants of the dependent variables. By considering alternative specifications, it is possible to gauge the sensitivity of findings to inclusion/exclusion of these explanatory variables.

Finally, the fourth specification added area fixed effects. These were binary variables for the SMSA in which the hospital was located and for non-SMSA hospitals, a binary variable measuring the hospital's state. When the dependent variable was more than one mutually exclusive alternative, I used multinomial logit analysis and did not include the fourth specification. With area fixed effects, there were too many parameters to estimate.

\section{Results: Medicare Analysis}

\section{Sample Characteristics}

The main GN sample consisted of 419,000 hospital discharges from 1,215 hospitals (table 5.1). Of these, over 16,000 hospital discharges were from forty-nine hospitals that changed from $G$ or $N$ to $F$ ownership status. Slightly over 6,000 discharges were observed from thirtyfive hospitals after the ownership conversion occurred. The main $F$ sample consisted of 56,000 discharges from 165 hospitals. Among these, thirty-two hospitals experienced a conversion from $F$ to $N$ or $G$ status during the observational period. Data were available from 
Table 5.1

Samples $^{\mathrm{a}}$

\begin{tabular}{lcc}
\hline Sample screen & Patients & Hospitals \\
\hline GN sample & 418,831 & 1,215 \\
GN to F subsample & 16,354 & 49 \\
GN to F after & 6,050 & 35 \\
& & \\
$F$ sample & 56,231 & 165 \\
$F$ to GN sample & 6,500 & 32 \\
$F$ to GN after & 2,331 & 20 \\
\hline
\end{tabular}

${ }^{a}$ Does not include observations drawn for analysis of coding of stroke versus transient ischemic attack (TIA).

twenty hospitals converting from $F$ to $N$ or $G$ ownership for the period after the conversion occurred.

I constructed a counterfactual sample. This sample of hospital discharges was matched to the conversion sample with respect to base ownership (GN or $F$ ). An artificial conversion year was randomly assigned to the admission. The frequency distribution of conversion years in the counterfactual sample matched the frequency distribution of actual conversions.

Given the large number of hospital discharges, there were many statistically significant differences between hospitals that did not convert and those that did convert, as well as for the pre versus postconversion comparisons (table 5.2). The differences, however, were often small. For the GN sample, these are the most noteworthy differences.

Hospitals converting from $G N$ to $F$ status experienced increases in the proportion of nonwhites that they admitted. Admissions through the emergency room fell, as did the receipt of patients from other hospitals. For converting hospitals, the mean DRG weight fell after conversion. A drop of 0.2 in the mean DRG weight for the five primary diagnoses is substantial. By contrast, in the counterfactual comparison group, the DRG weight rose in the after group in contrast to the before group. The mean DxCG score rose from 2.1 to 2.2 before versus after conversion to $F$ status. For the comparison group, the mean score rose from 2.0 to 2.2. Medicare payment is based on the DRG weight but not the DxCG score. This comparison suggests something less than a massive change in upcoding for purposes of obtaining higher Medicare payments postconversion to $F$ ownership. 


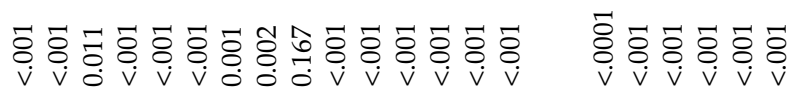

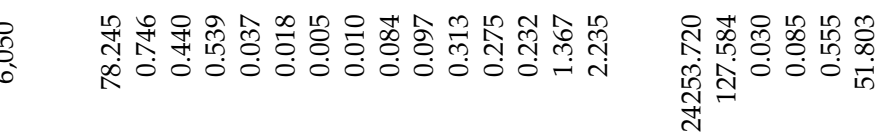

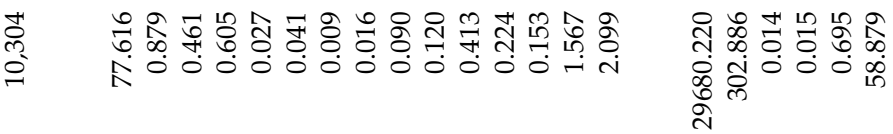

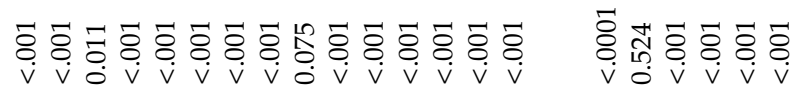

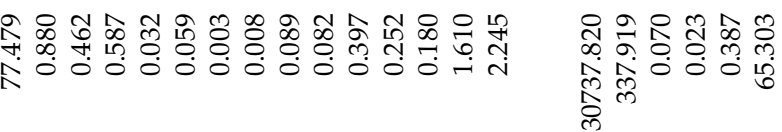

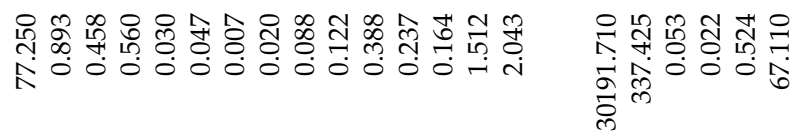

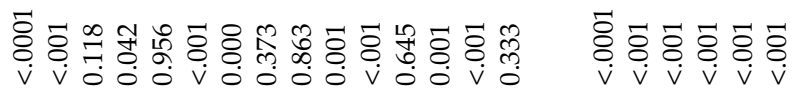

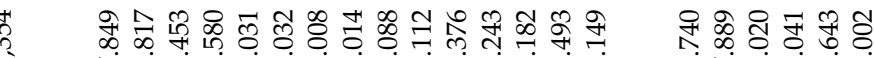

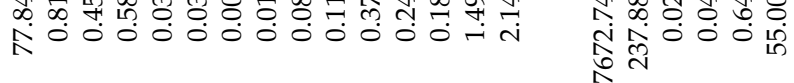
กิ

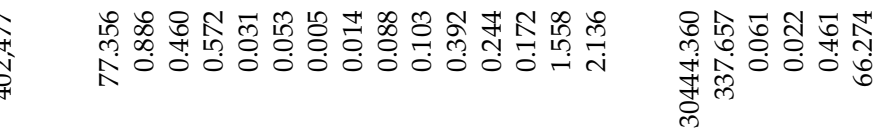




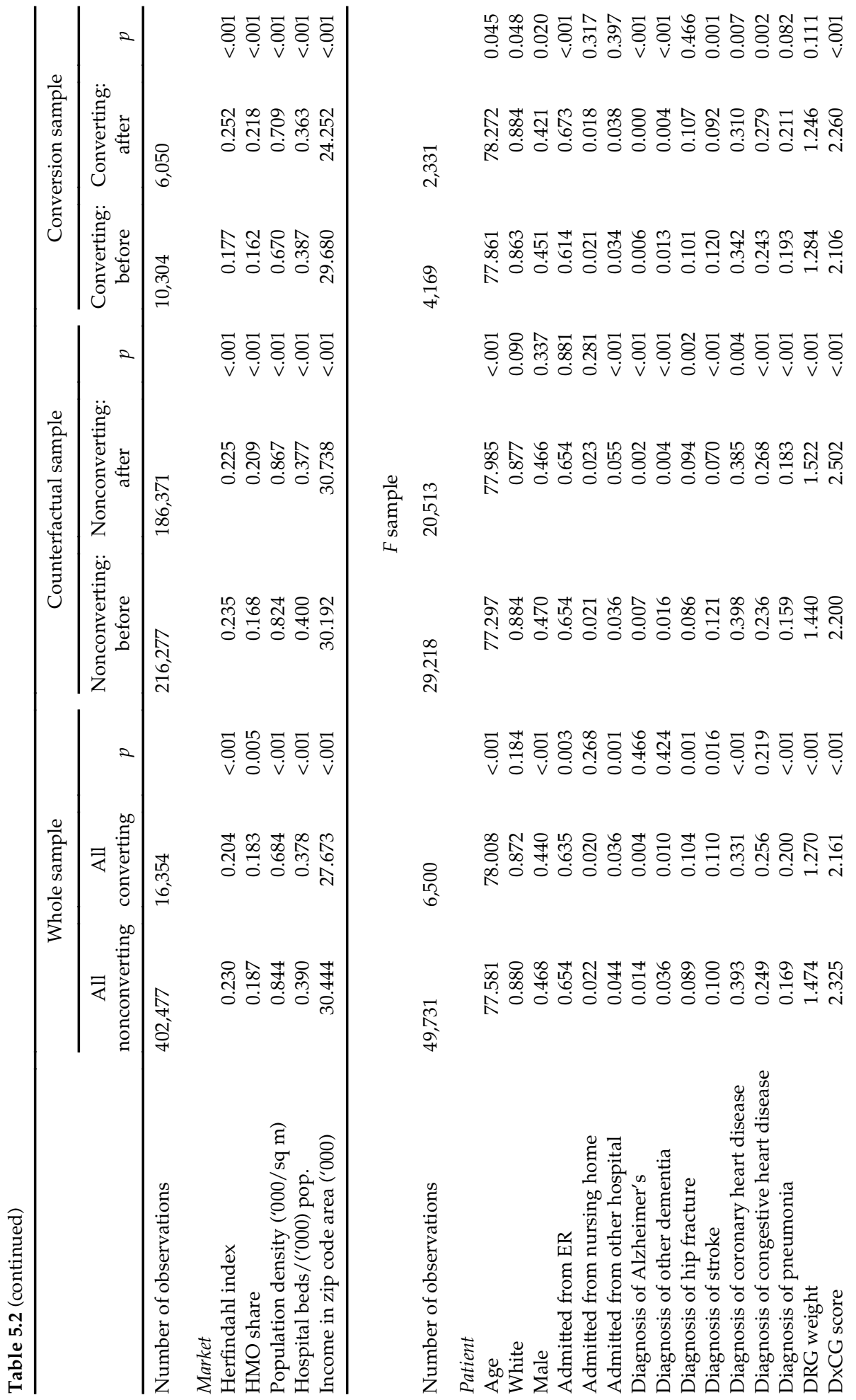




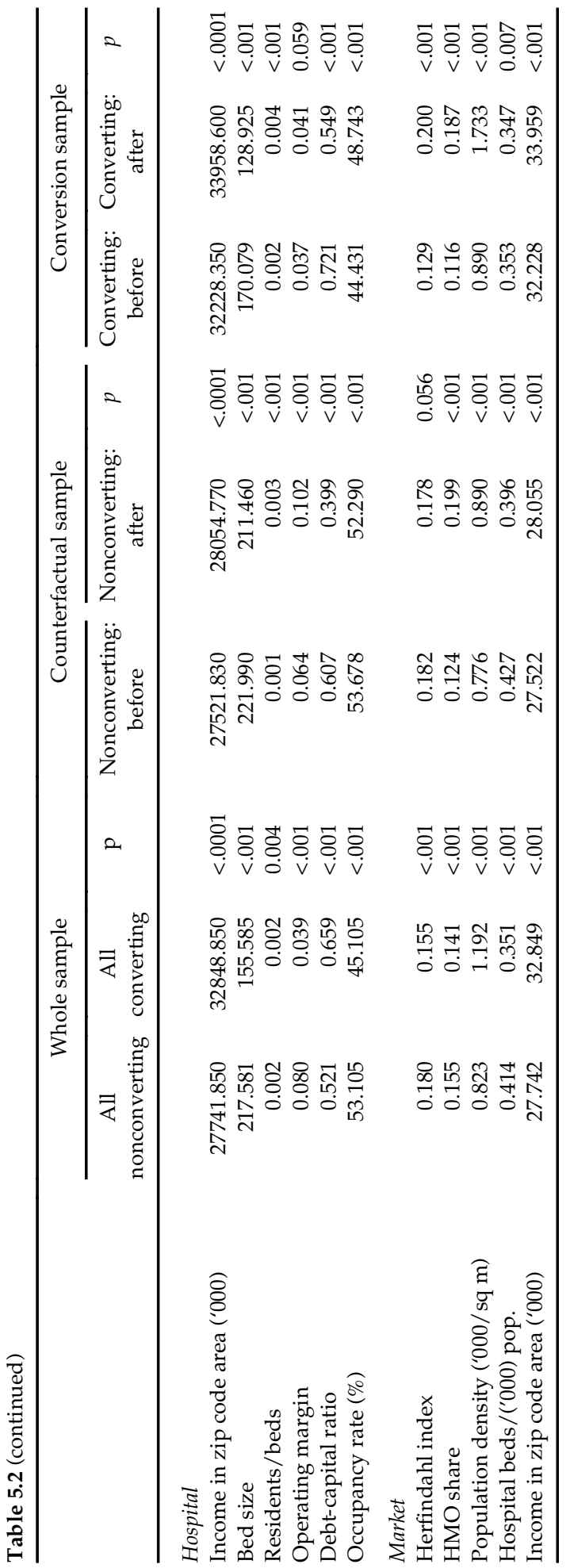


In the counterfactual group, mean bed size remained about constant. Among converting hospitals, however, mean bed size fell by more than 50 percent after conversion. The number of residents per bed rose among converting hospitals, but this change was fully attributable to the reduction in beds. Operating margins in converting hospitals rose dramatically. Before conversion, the mean margin per discharge in converting hospitals was 0.015. After conversion, the mean was 0.085. By contrast, in the counterfactual group, operating margins remained about constant. The debt-to-assets ratio fell for both converting and nonconverting hospitals, but much more for those hospitals that did not convert. The mean occupancy rate fell from 57 to 52 percent for converting hospitals, in spite of the substantial reduction in bed size. For nonconverting hospitals, however, mean occupancy decreased only from 67 to 65 percent. Clearly, low occupancy rates were far more characteristic of hospitals converting from GN to $F$ than among hospitals that did not convert.

For converting hospitals, the Herfindahl index rose, suggesting a decline in competition. By contrast, for hospitals that did not convert, the Herfindahl index was unchanged. Personal per-capita income fell on average in the zip code areas in which the converting hospitals were located. But there was no change in income among nonconverting hospitals.

Many of the patterns were similar in the $F$ sample. For example, the mean DRG weight declined slightly after conversion to GN status. By contrast, for hospitals in the counterfactual group, the mean DRG rose after the conversion. The major difference was in the operating margin. Margins increased much more among nonconverting than among converting hospitals. As seen above, for GN hospitals, margins increased appreciably for hospitals converting to $F$ ownership.

The mean in-hospital mortality rate in the GN sample hospitalized in nonconverting hospitals was 8.1 percent (table 5.3). For those hospitalized in converting hospitals, the mean mortality rate was 7.9 percent. Even with this large sample, this difference was not statistically significant at conventional levels. Although mortality fell from 8.2 percent before to 7.6 percent after conversion in converting hospitals, this difference was not statistically significant at conventional levels $(p=0.19)$. In the counterfactual sample, the decline was apparently larger, from 8.7 percent in the counterfactual before group to 7.5 percent in the after group $(p<0.0001)$. The decrease reflects the secular decrease in inpa- 


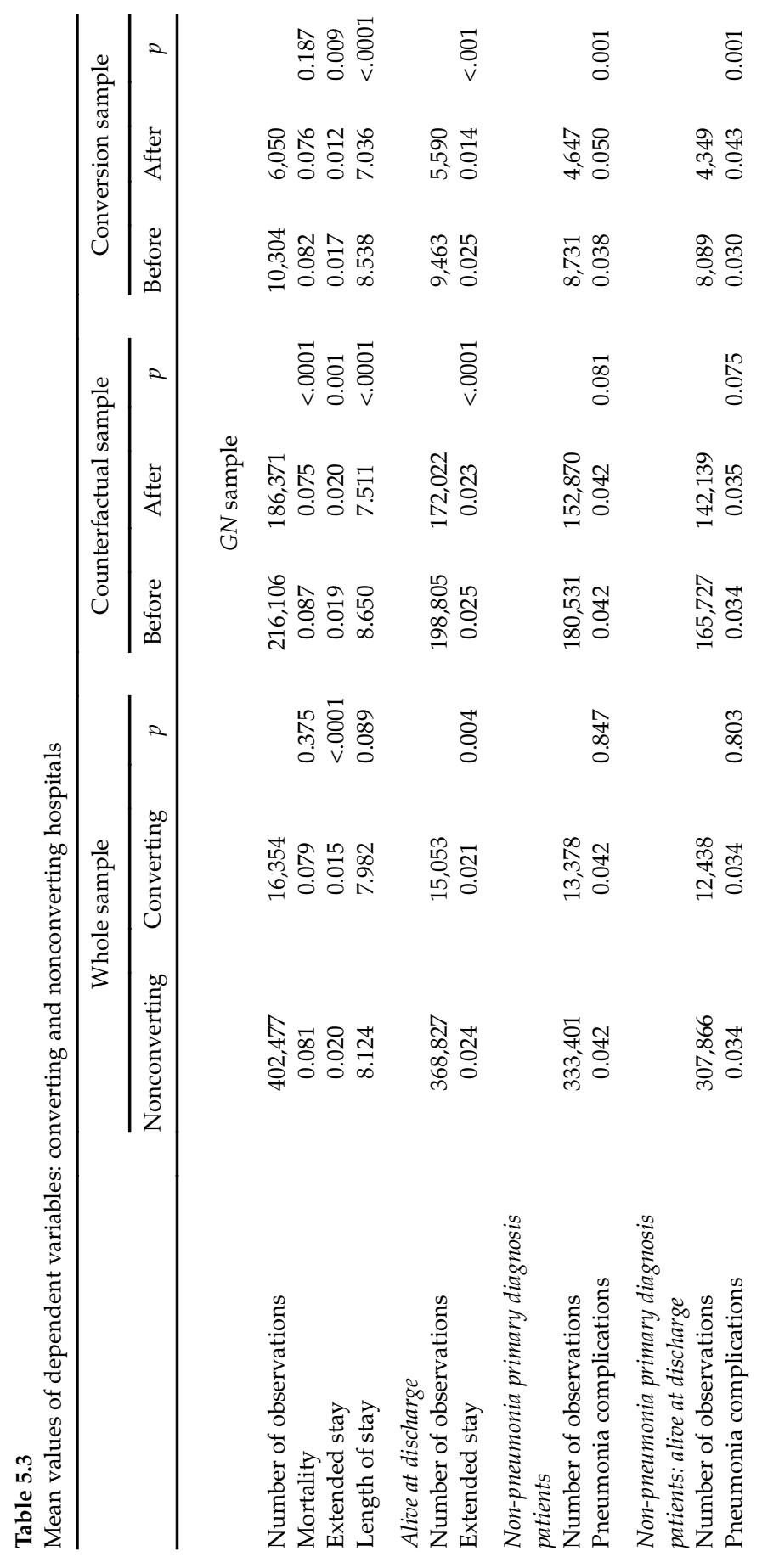




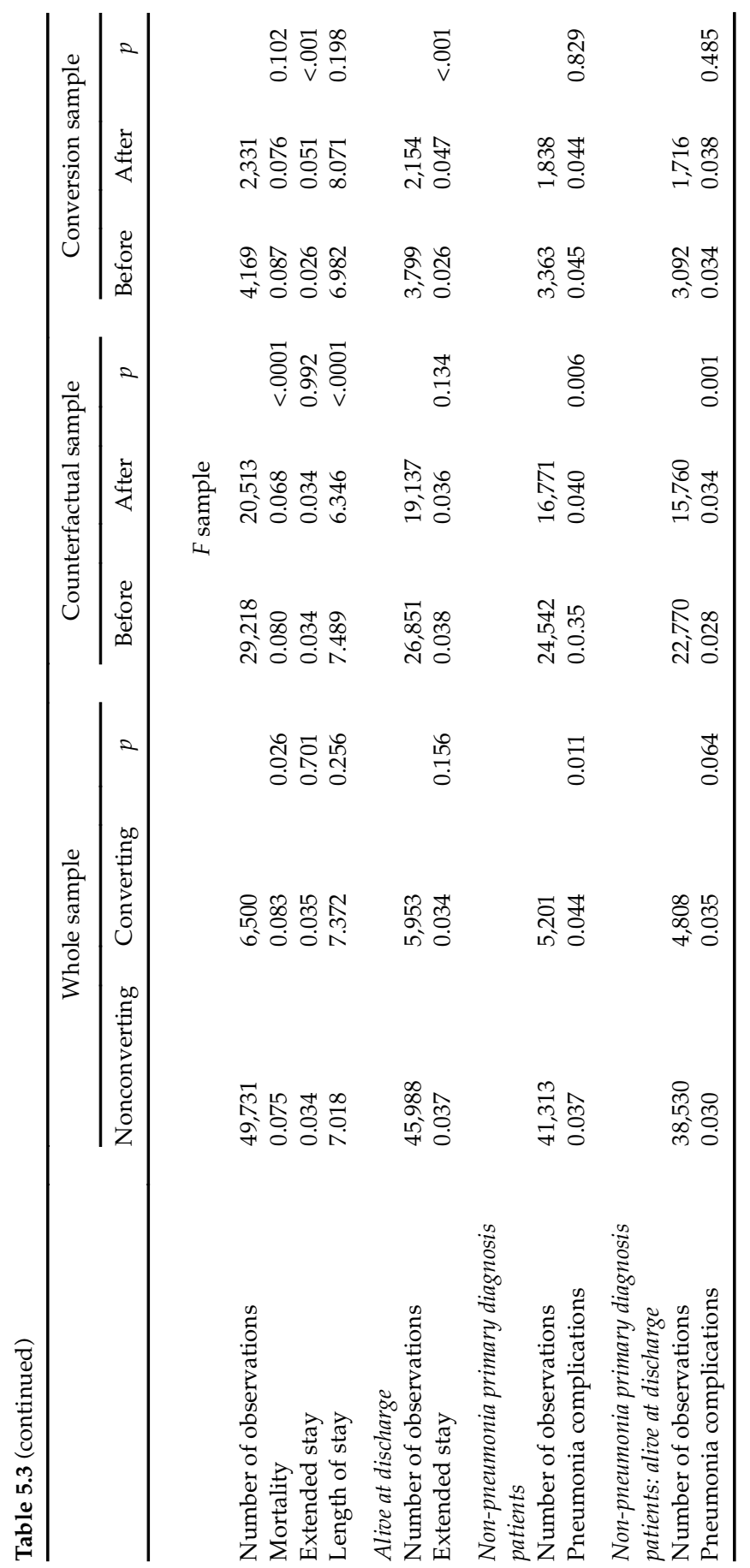


tient mortality, which apparently was not as favorable among hospitals that changed from $G N$ to $F$ ownership status.

The rate of pneumonia complications rose in hospitals converting from $G N$ to $F$ after conversion. The increase was from 3.8 to 5.0 percent $(p=0.001)$. In the counterfactual sample, there was no change. Rates of extended stays, as did mean length of stay, declined much more in hospitals that were involved in ownership conversions than in those not involved in a conversion, implying that hospitals converting from $G N$ to $F$ made a substantial effort to reduce the very long lengths of stay. Mean length of stay declined in both converting and nonconverting hospitals, but more so in the former.

For the $F$ sample, mortality rates declined by the same absolute amount for those hospitals that converted versus the counterfactual sample, but those that converted had a higher mortality rate in the before period. Pneumonia complication rates rose among those hospitals that remained for-profit, but these rates did not rise among those that converted from for-profit to either government or private nonprofit status. The rate of extended stays rose dramatically among hospitals in the converting group, but remained constant among those that did not convert, a very different pattern from hospitals in the GN sample.

Thus, overall, judging on the basis of mean values alone, a couple of negative features emerge in the GN-to- $F$ case. The in-hospital mortality experience was not as good among hospitals that converted from $G N$ to $F$ status. Furthermore, pneumonia complication rates rose among those hospitals that converted from $G N$ to $F$ and among those for-profit hospitals that did not convert. Length of stay was related to ownership, with for-profit hospitals achieving lower lengths of stay overall.

\section{Effects of Ownership Type Conversions on Inpatient Mortality, Pneumonia Complications, and Extended Length of Stay}

The multivariate analysis of ownership type conversion effects begins with effects on inpatient mortality, and pneumonia complications during the stay occurring to patients admitted for stroke, hip fracture, coronary heart disease, and congestive heart failure (table 5.4). In the first specification in the GN sample, in patient mortality fell after conversion to $F$ ownership. The decline was 0.8 percent on average, or about 10 percent relative to mean mortality. (The numbers in the table in brackets are marginal effects-changes in the probability of an outcome for a 


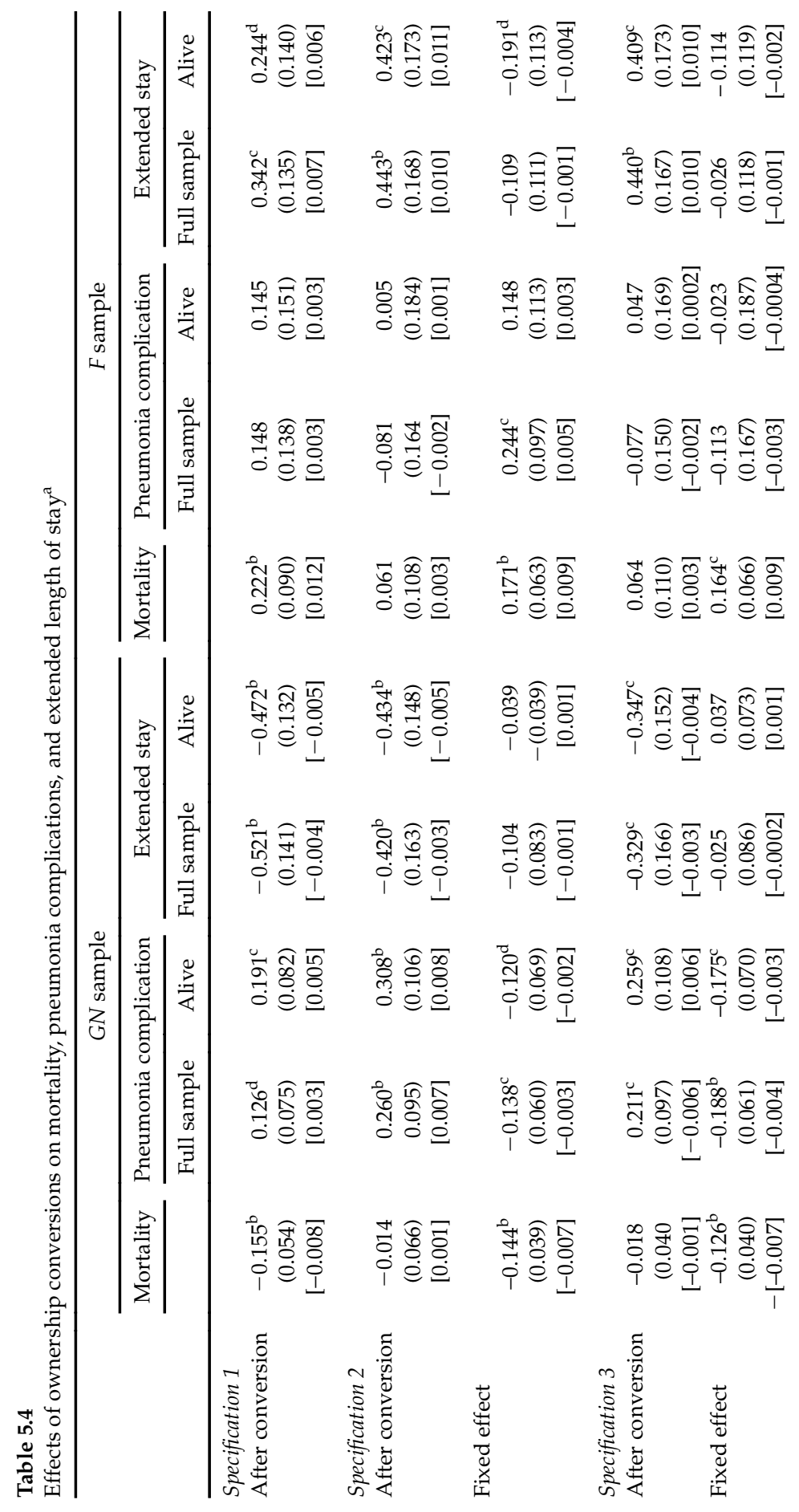




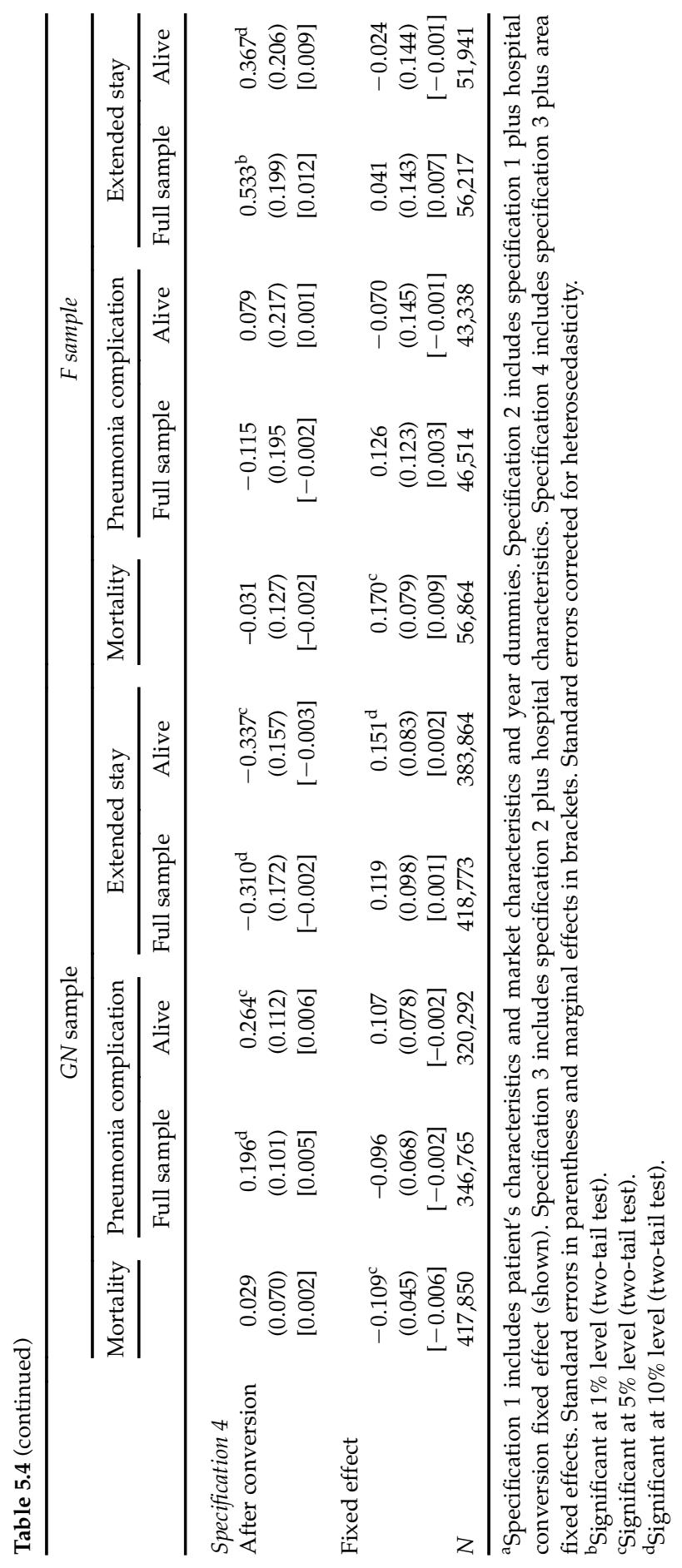


change in binary or a unit change in explanatory variables for continuous variables. ${ }^{9}$ ) In the remaining specifications, however, there was no change in inpatient mortality after conversion to $F$ ownership. The results for the conversion fixed effect in specifications 2 to 4 imply that hospitals that converted from $G$ or $N$ to $F$ ownership tended to have lower mortality rates. That is, if anything, the new owners selected GN hospitals with relatively good mortality records.

In the $F$ sample, the first specification implies a mortality increase after conversion to $G$ or $N$ status with an associated marginal effect of $0.012(p=0.01)$. However, the after conversion parameter becomes statistically insignificant in the other, more complete specifications. In general, the results on the key parameters of interest-the binary variables for after conversion and the conversion fixed effect-are quite sensitive to changes in equation specification. Thus, again, ownership conversion had no effect on inpatient mortality.

The proportion of patients with very long stays declined in the $G$ and $N$ to $F$ case and rose for conversions in the opposite direction, supporting the descriptive results presented above in table 5.3. Pneumonia complications rose after conversion among patients admitted to hospitals that converted to $F$ ownership. The reverse occurred among patients admitted to hospitals that converted from $F$ ownership. This conclusion holds for the full sample of Medicare patients in the four primary diagnosis categories (excluding those admitted with a primary diagnosis of pneumonia) and for a sample that excludes such patients who died during their stays.

To conserve space and permit focus on the key parameter estimates and associated marginal effects, table 5.4 does not include most of the parameter estimates in the model. Table 5.5 shows complete specifications from the GN sample for four dependent variables shown previously, but the table does not show area fixed effects. Almost all the parameter estimates on the patient variables are statistically significant at conventional levels and have plausible signs.

Results for the hospital and market variables are somewhat more mixed. The measures of financial distress show no consistent effects on outcomes. For example, hospitals with an operating loss (no profit) experienced higher rates of pneumonia complications and a higher mean length of stay, but there were no effects on either inpatient mortality or the rate of extended stays. Death rates were higher in larger hospitals but lower in major teaching hospitals. The result for hospital size plausibly reflects case mix not otherwise measured. The coefficient on ex- 


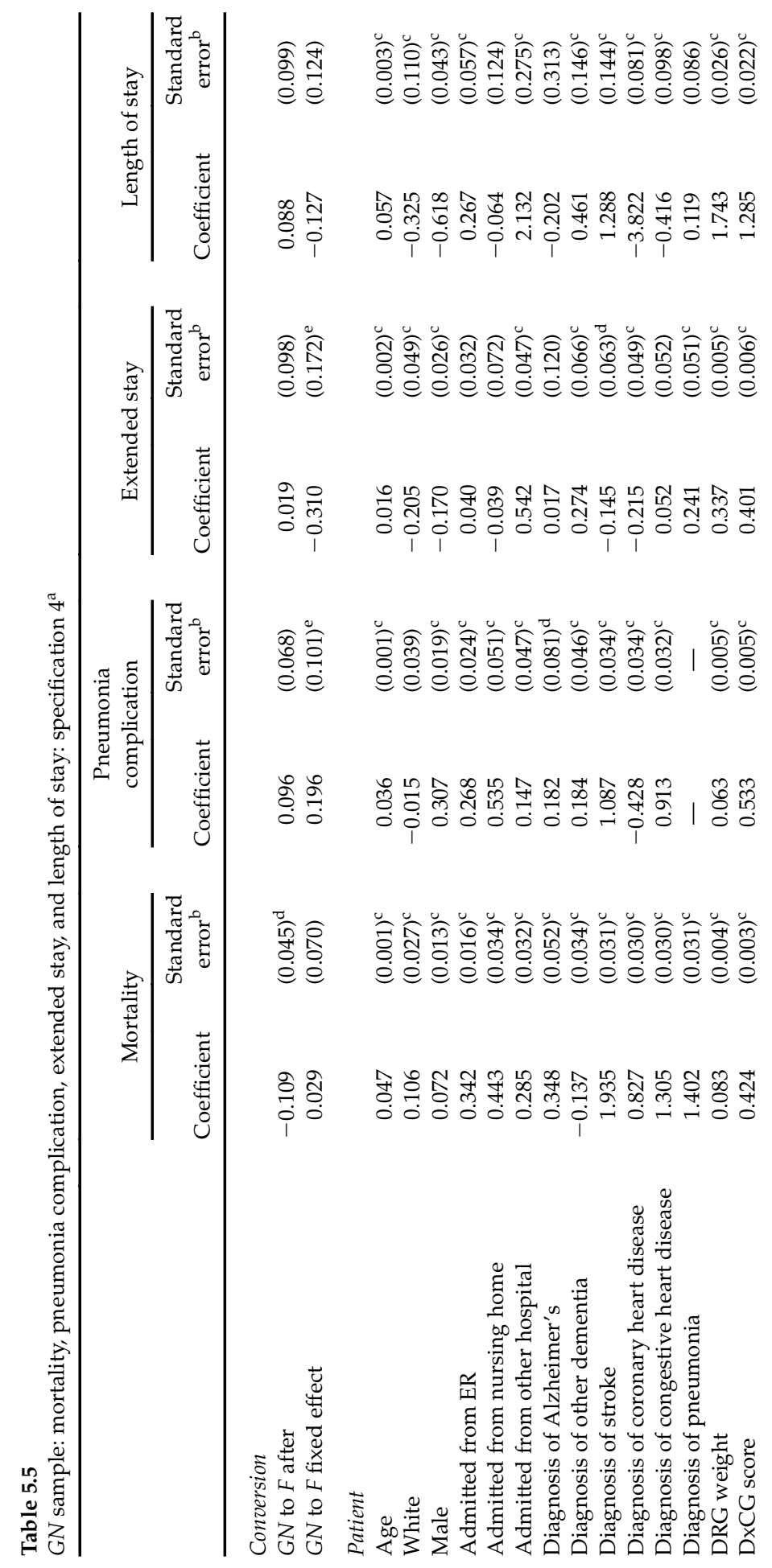




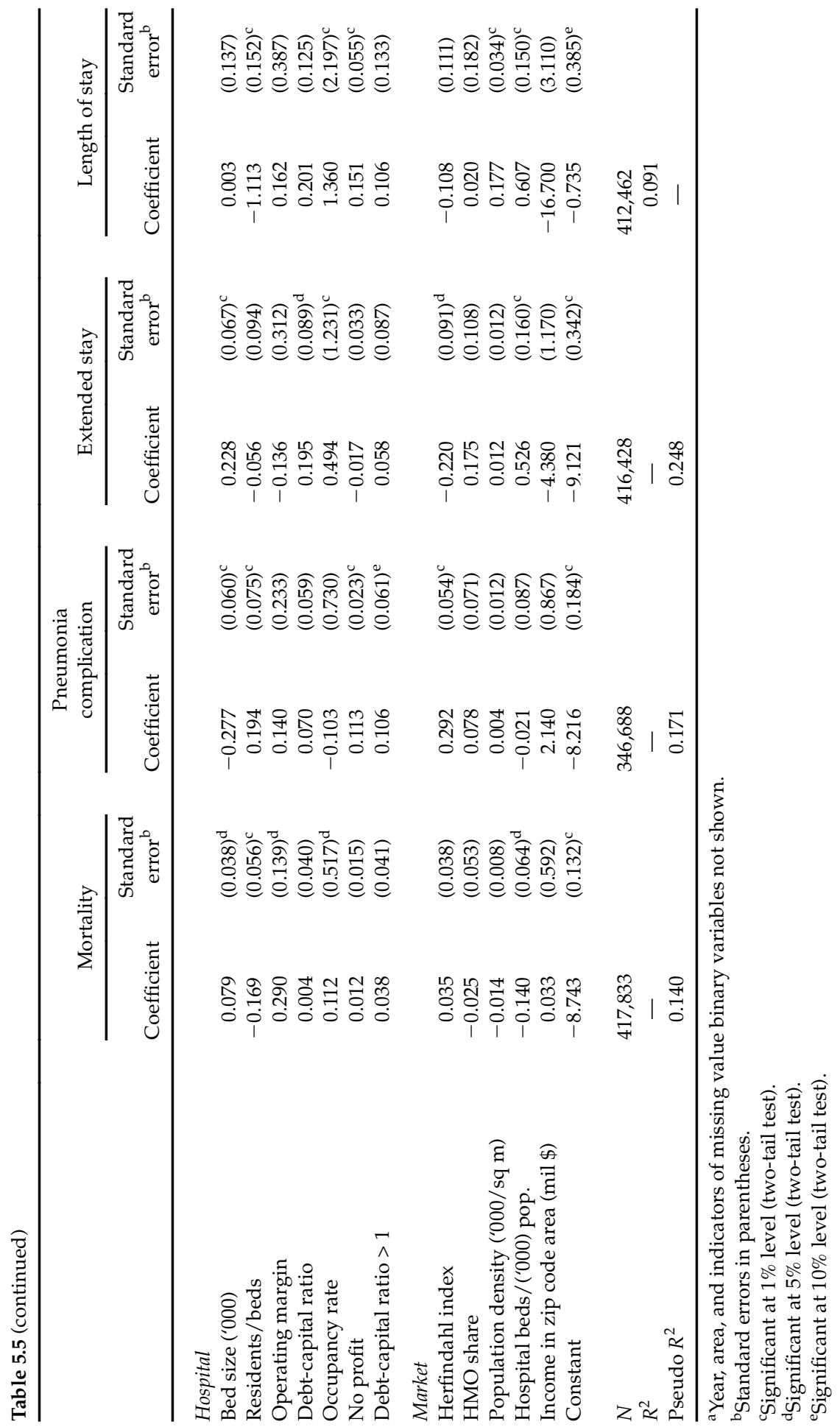


tended stay is positive and statistically significant at conventional levels.

Finally, to the extent that hospitals converting from $G N$ to $F$ status achieved shorter lengths of stays after ownership conversion, was this achieved by increased rates of transfers to nursing homes or to other hospitals? To determine the answer to this question, multinomial logit analysis of the place to which the person was discharged after leaving the hospital was conducted (table 5.6). The four destinations were home (reference group), death, nursing home, and other hospital. The analysis controlled, among other factors, for source of admission (nursing home, other hospital, emergency room, home) because patients were more likely to return to the place from which they came to the hospital. But given the number of parameter estimates in a multinomial format, area fixed effects were not included. As in all of the other analyses, year binary variables were included. Results shown in the table 5.6 are based on specification 3.

In the GN sample, 8.1 percent of persons died in the hospital, 15.3 percent were transferred to a nursing home, 10.1 percent were transferred to another hospital, and the remaining two-thirds (65.5 percent) returned home. The pattern of discharge destinations was similar for the $F$ sample, with a slightly lower percentage of patients returning home and a somewhat higher percentage being transferred to other hospitals-possibly reflecting their smaller bed size.

Holding other factors constant, the rate of discharges to other hospitals increased after conversion for GN to $F$ hospitals (relative to discharge to home). The associated marginal effect of 0.039 is substantial relative to the sample mean transfer rate (about 40 percent of the sample mean). In view of the dramatic drop in bed size among GN-to- $F$ converting hospitals noted earlier, an increase in the transfer rate to other hospitals is not surprising. In the $F$ sample, discharges to nursing home increased after conversion, but the associated marginal effects were very small.

\section{Upcoding of Diagnoses}

For the measures studied, there is no evidence that ownership conversion from $G N$ to $F$ ownership status increased the rate of upcoding (table 5.7). In the analysis of mean DRG weight of the five primary diagnoses included in the Medicare analysis, the DRG weight fell after conversion from GN to $F$. In this specification, many hospital character- 


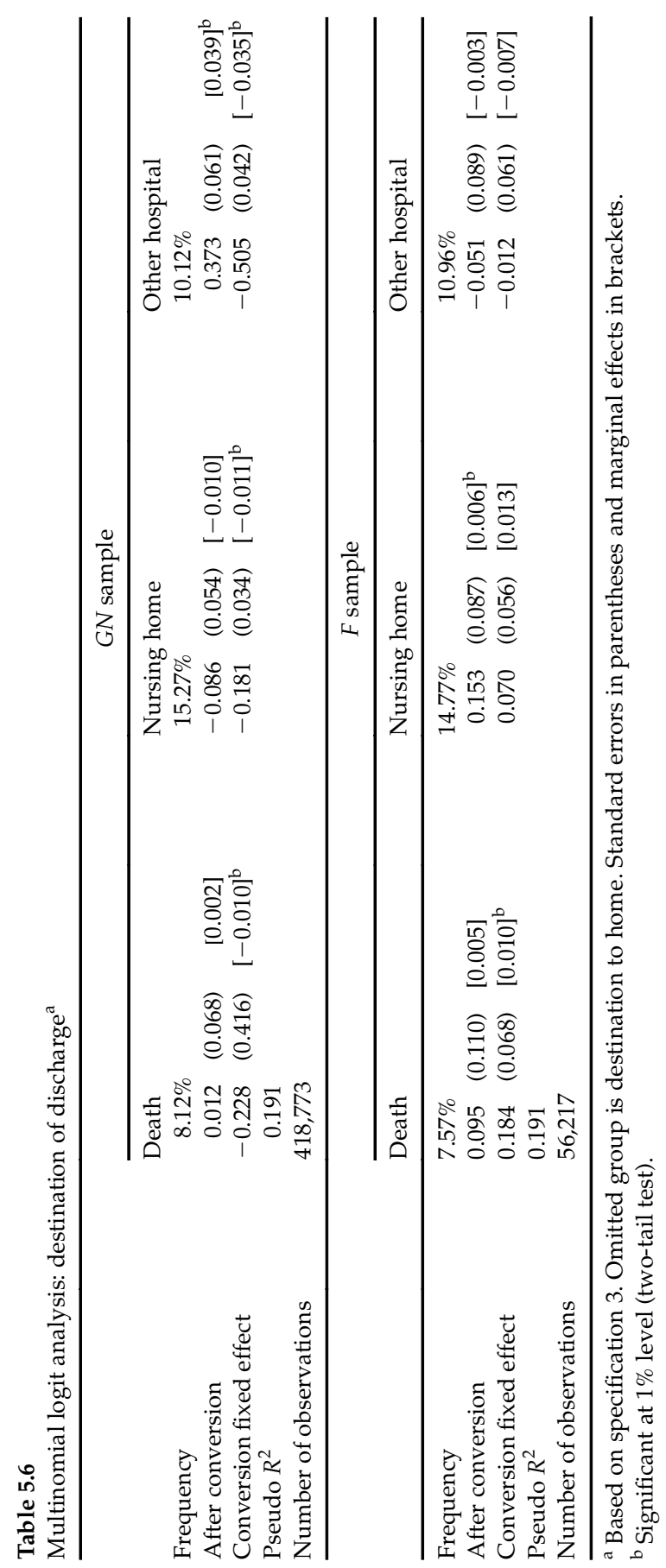


istics, including bed size, were held constant. Thus, the results for ownership conversion do not reflect just downsizing and loss of some sophisticated product lines. Of course, a decrease in the mean DRG may have reflected subtle changes in case mix. To the extent that this occurred, it more than obscures any change in upcoding for the five primary diagnoses included in this analysis that may have occurred. For coding of transient ischemic attack (TIA) versus stroke, there was an increase in the proportion of TIAs (significant at the 10 percent level) following conversion from $G N$ to $F$ status. By contrast, hospitals that converted from $F$ to $G N$ did have higher DRG weights after conversion. Similarly, the proportion of cases coded as stroke rather than TIA rose.

\section{Results: Patients Under Age 65}

\section{Payer Mix after Ownership Conversion}

As discussed in the previous section, there is widespread concern that ownership conversions work to the disadvantage of underserved populations. However, empirical evidence on actual effects has been mixed. Table 5.8 presents key results of a multinomial analysis of anticipated source of payment. Since the payment categories are confined to the primary source of payment, they are mutually exclusive. For patients who were between the ages of 1 and 64 at the admission date and were admitted to a facility in the GN sample, the probability of having Medicare, other government insurance, or Medicaid, or being classified as a self-pay/no charge patient increased after conversion to $F$ status. $G$ or $N$ hospitals acquired by $F$ owners tended to be those that had relatively low proportions of Medicaid and self-pay/no charge patients, or Medicare (disabled, end stage kidney disease) patients. However, the tendency to eschew the poor and the disabled was not sustained after conversion.

Results for hospitals converting from $F$ to $G N$ ownership are mixed. The proportion of self-pay/no charge patients fell after conversion to GN status. For the sample of births, holding other factors constant, hospitals converting from GN to $F$ were more, not less, likely to admit nonprivately insured patients after the conversion occurred (table 5.9). This finding is very sensitive to changes in equation specification. The conversion fixed effect is negative and the associated marginal effect is substantial. The implication is that for-profit organizations were more likely to acquire hospitals that were relatively oriented to privately in- 


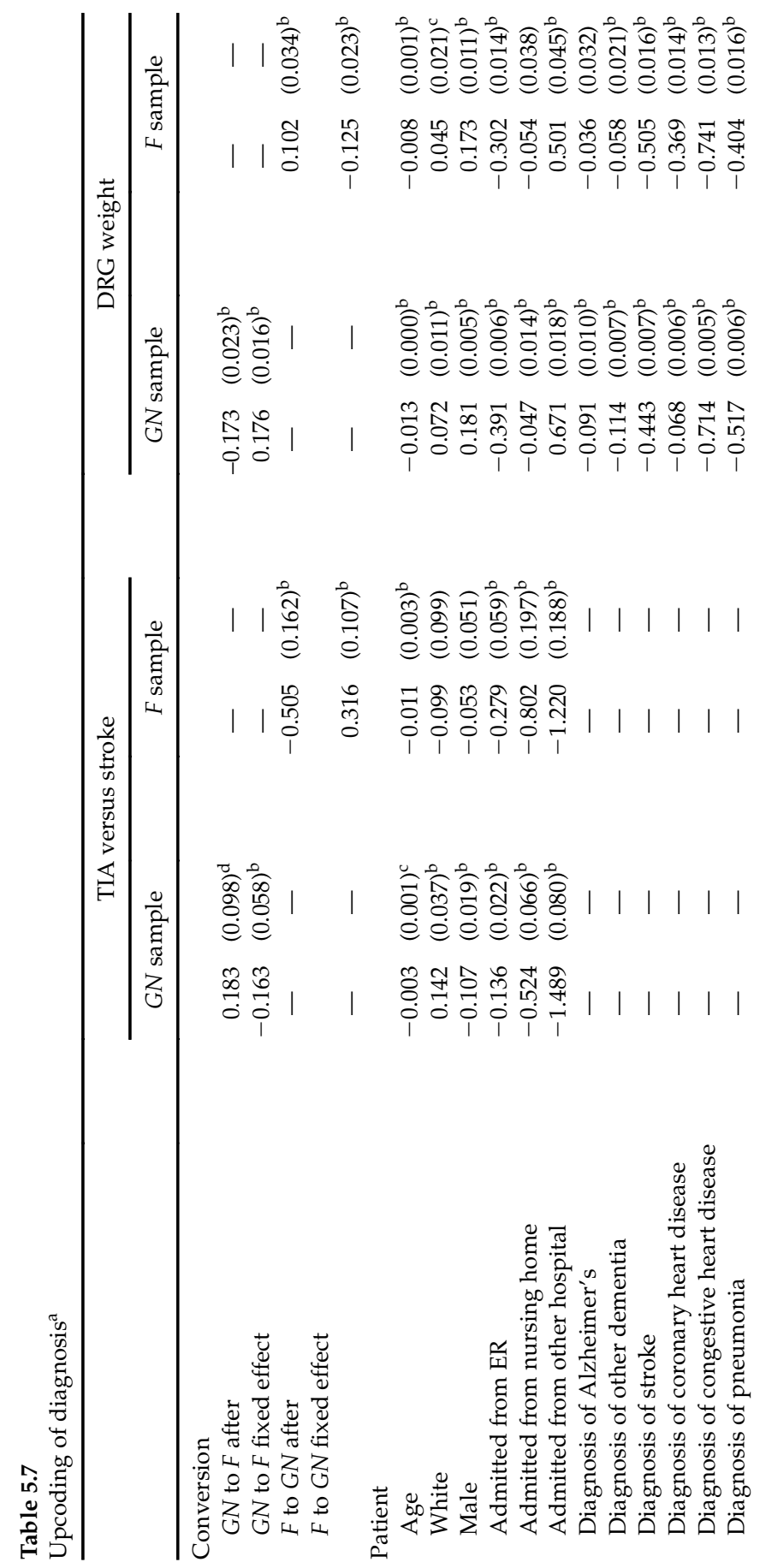




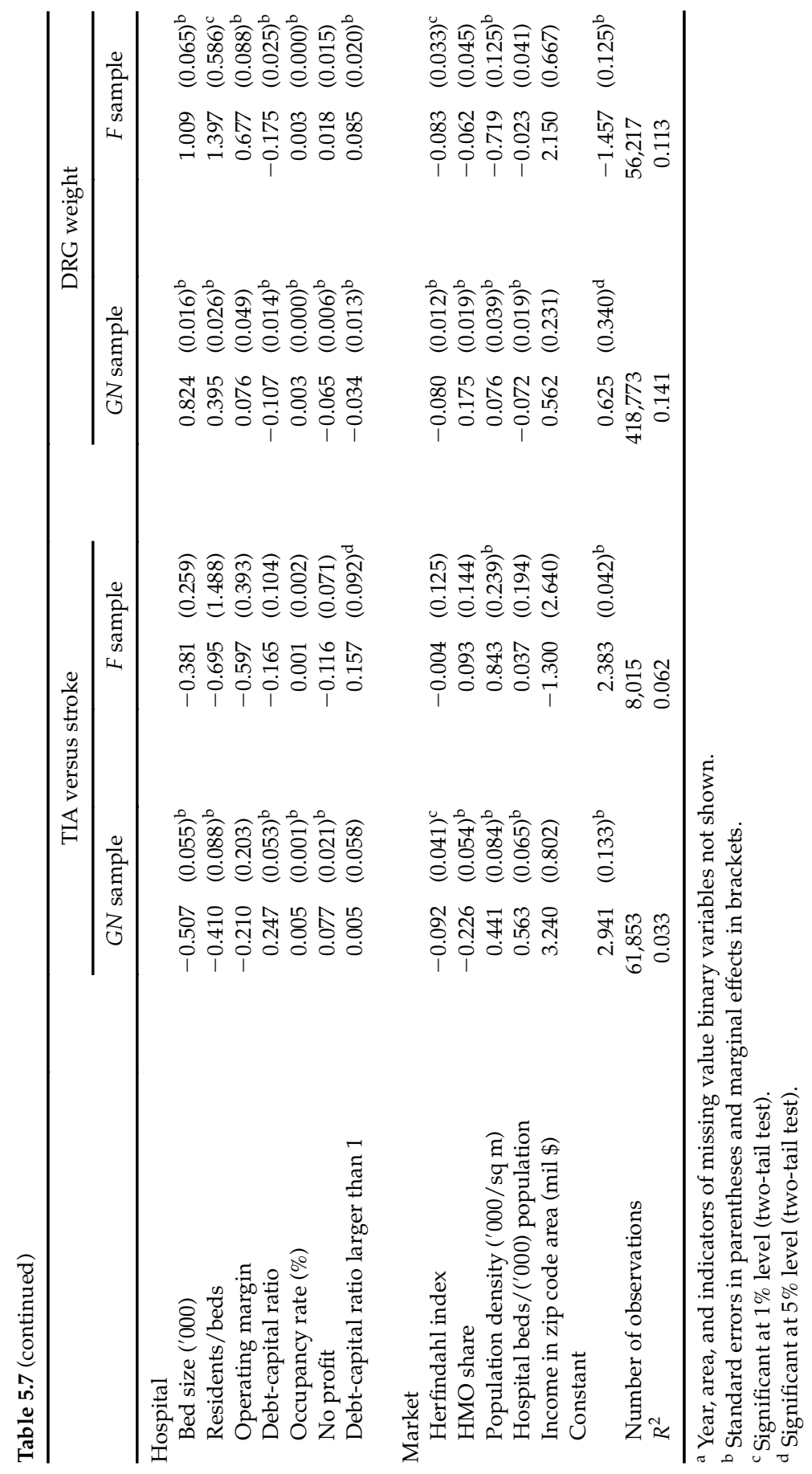




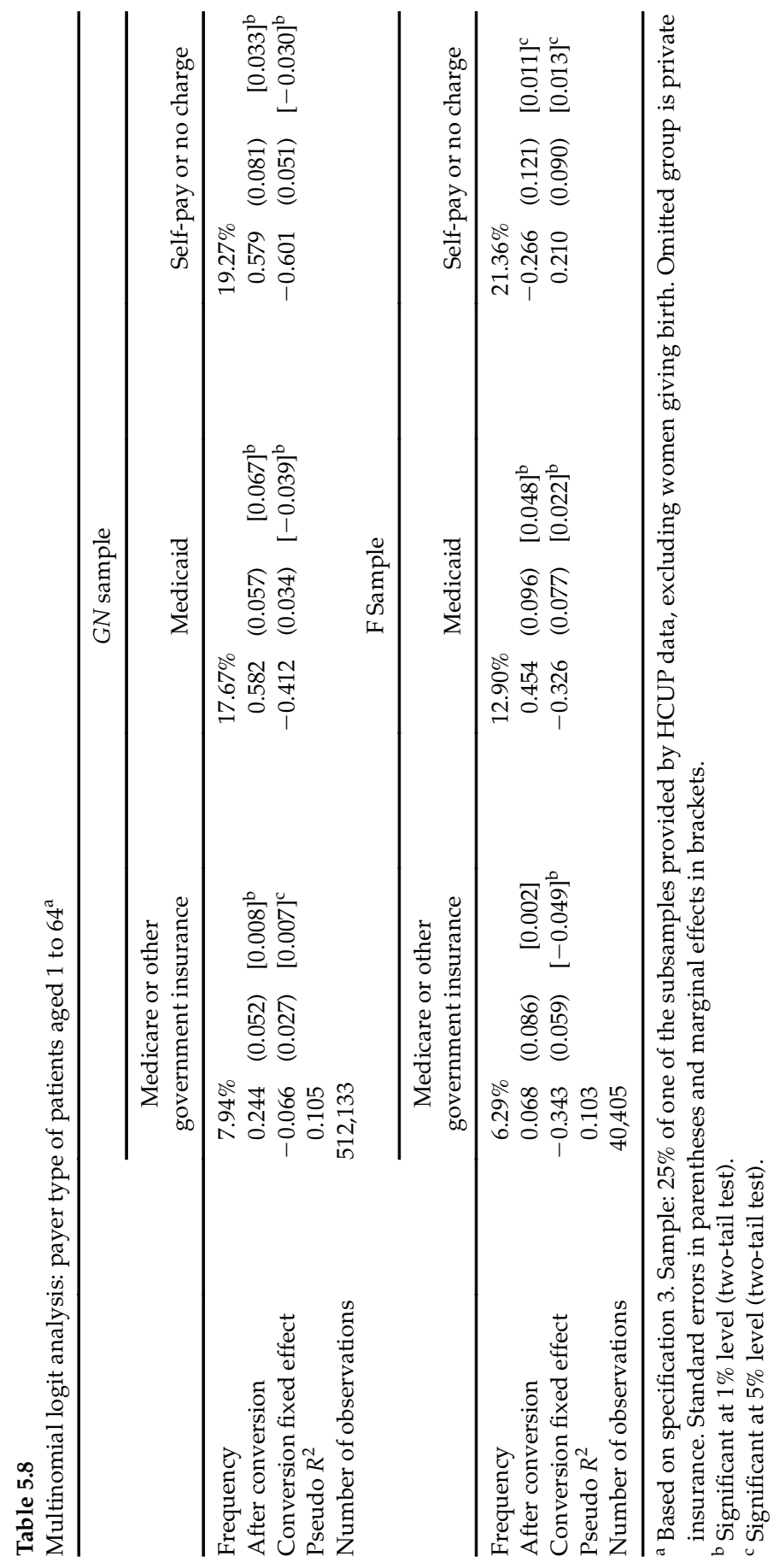


Table 5.9

Logit analysis of probability of payment other than private insurance for labor delivery, less than two-day stay, and vaginal birth ${ }^{\mathrm{a}}$

Probability of payment other than private insurance $n$

\begin{tabular}{|c|c|c|c|c|c|c|}
\hline After conversion & 0.916 & $(0.046)$ & {$[0.224]^{\mathrm{b}}$} & 0.884 & $(0.107)$ & {$[0.218]^{\mathrm{b}}$} \\
\hline Conversion fixed effect & -0.417 & $(0.026)$ & {$[-0.098]^{b}$} & -0.187 & $(0.083)$ & {$[-0.044]^{\mathrm{c}}$} \\
\hline Number of observations & 558,268 & & & 32,527 & & \\
\hline & 0.188 & & & 0.213 & & \\
\hline \multicolumn{7}{|c|}{ Probability of less than two-day stay } \\
\hline After conversion & -0.391 & $(0.056)$ & {$[-0.025]^{b}$} & -0.206 & $(0.117)$ & {$[-0.017]^{\mathrm{d}}$} \\
\hline Conversion fixed effect & -0.347 & $(0.028)$ & {$[-0.023]^{b}$} & -0.085 & $(0.092)$ & {$[-0.007]$} \\
\hline Number of observations & 566,927 & & & 32,635 & & \\
\hline & 0.015 & & & 0.024 & & \\
\hline \multicolumn{7}{|l|}{ Probability of vaginal birth } \\
\hline After conversion & -0.340 & $(0.049)$ & {$[-0.025]^{b}$} & 0.123 & $(0.103)$ & [0.024] \\
\hline Conversion fixed effect & 0.252 & $(0.024)$ & {$[0.025]^{\mathrm{b}}$} & 0.299 & $(0.075)$ & {$[0.061]^{\mathrm{b}}$} \\
\hline Number of observations & 567,605 & & & 32,635 & & \\
\hline Pseudo $R^{2}$ & 0.293 & & & 0.315 & & \\
\hline
\end{tabular}

${ }^{a}$ Based on specification 3. Standard errors corrected for heteroscedasticity. Standard errors in parentheses and marginal effects in brackets.

${ }^{\mathrm{b}}$ Significant at $1 \%$ level (two-tail test).

c Significant at 5\% level (two-tail test).

d Significant at $10 \%$ level (two-tail test).

sured patients, but after conversion, there was a major increase in nonprivately insured patients. The marginal effect is 0.224 . Since time fixed effects were included, the marginal effect for the after-conversion dummy does not reflect a secular growth in persons not covered by private insurance. Patterns for conversions from $F$ to $G N$ status were quite similar to those from GN to $F$.

\section{Changes in Length of Stays: Birth Sample}

There is widespread concern that the length of hospital stays for labor and delivery have declined to unsafe levels. Such reductions are said to be motivated mostly by a desire to increase profit. Some states have implemented laws to restrict the ability of health care providers to limit stays for labor and delivery to less than two days. Table 5.9 shows that the probability of a less-than-two-day stay declined after ownership conversion, both for hospitals that converted from $G N$ to $F$ status and those that converted in the opposite direction. 


\section{Changes in the Probability of Vaginal Births}

The proportion of vaginal births declined after hospitals converted from government or not-for-profit to for-profit status (table 5.9). For hospitals that converted from $F$ to $G N$ status, there was an increase in the probability of vaginal births, but this increase was not statistically significant at conventional levels.

\section{Discussion, Conclusions, and Implications}

The main question addressed by this paper is whether or not the market for hospitals is fundamentally broke. In my review of the literature of cross-sectional evidence on differences in hospital behavior by ownership type, I conclude that hospitals with various types of ownership were more alike than different (Sloan 2000). With longitudinal data on the same set of hospitals (panel data), the research focus has been on changes in behavior for the same hospital following a change in ownership. With a panel, isolating the effect of the change in ownership can be done more precisely.

In many respects, the empirical evidence from hospital conversions is reassuring. In particular, in this study, I did not find that in-hospital mortality changed as a result of changes in ownership type. Payer mix, including the proportion of persons admitted without health insurance, was not affected. On the whole, hospitals' missions appear to be preserved postconversion. In large part, constancy of mission has been safeguarded by contract provisions that are made part of the agreement between the buying and selling hospitals at the time of the transaction. The analysis presented in the previous section did not reveal systematic upcoding by hospitals that converted to for-profit ownership status. Thus, the upcoding for pneumonia and respiratory infections reported in an earlier study does not appear to generalize to other diagnoses.

However, rates of pneumonia complications rose following conversions from government or private nonprofit to for-profit ownership. In another recent study cited in this paper, mortality rates following discharge rose appreciably following conversion at hospitals that converted from government or private nonprofit to for-profit ownership, especially during the first two years after the conversion occurred. One reason that there would be no change in in-hospital mortality, but an increase in mortality observed at thirty days, six months, and one year following admission to the hospital, may be that hospitals 
converting to for-profit ownership reduced lengths of hospital stay disproportionately.

The evidence pointing to some adverse effects of conversions is a reason for concern and should affect public policy regarding hospital ownership conversions. There is a clear role for public oversight. Success is not guaranteed-the "Allegany system debacle," where effective public oversight was lacking, is a case in point. Communities that place their hospital assets for sale would do well to exercise due diligence. This may take the form of oversight by the state attorney general or the state certificate of need agency, as well as local elected officials. Practices such as upcoding should be monitored by hospital compliance programs. Some public oversight of hospital staffing during the years immediately following conversion seems warranted based on the empirical evidence.

Is there a chance that this study has failed to document important changes in quality of care and/or public goods provision associated with changes in hospital ownership status? Almost certainly yes. The issues involved are complex, and there are so many kinds of outcomes. This consideration adds further force to the conclusion that scrutiny should be case-specific. Rather than conclude that all conversions of a given type are "bad" or "good," public policy should recognize the heterogeneity and multiplicity of outcomes.

\section{Notes}

I acknowledge the capable research assistance of Jingshu Wang, Department of Economics and Center for Health Policy, Law, and Management, Duke University, and the grant, Hospital Ownership Conversions, from the Robert Wood Johnson Foundation and administered by the Academy for Health Services Research and Health Policy.

1. Of course, the two aspects are related. If there are many concessions on nonprice dimensions of the transaction, the price should reflect this.

2. This result is consistent with the finding by Thorpe et al. (2000) that margins increased after conversion to for-profit status, mainly because of expense reductions.

3. In some unpublished work, colleagues and I followed the suggestion to include a binary for trauma center in analysis of survival following inpatient stays. The variable typically did not affect outcomes. One might argue that a trauma center is endogenous to ownership.

4. Their technique includes the equivalent of hospital fixed effects.

5. A more complete discussion of the effects of hospital competition on quality of care is beyond the scope of this paper. On this subject, see, for example, Kessler and McClellan (2000). 
6. This has been documented by others as well. See, for example, Eldenburg et al. (2001).

7. This result is consistent with a view advanced by Lakdawalla and Philipson (1999). They argued that nonprofit behavior should not affect for-pro fit behavior because the latter, by virtue of the lack of tax advantages and charitable endowments, are the marginal firms and hence influence market outcomes (price, quality, etc.).

8. Medicare compliance, coding, self-referral, and joint ventures have become major issues to hospitals. See, for example, a newsletter for hospital administrators explicitly devoted to these issues: Eli Research, "Hospital Compliance Alert."

9. In table 5.4, all explanatory variables shown are binaries.

\section{References}

American Hospital Association (1976). Hospital Statistics. Chicago, IL: AHA, 1976.

American Hospital Association (1979). Hospital Statistics. Chicago, IL: AHA, 1979.

American Hospital Association (2001). Hospital Statistics. Chicago, IL: AHA, 2001.

Anderson, Ruth, Charlene Allerd, and Frank A. Sloan (2001). "Effects of Hospital Conversions on Organizational Decision Making and Service Coordination," unpublished.

Blumenthal, David, and Joel S. Weissman (2000). "Selling Teaching Hospitals to Investor-Owned Hospital Chains: Three Case Studies," Health Affairs 19(2):158-166.

Burns, Lawton R., John Cacciamani, James Clement, and Welman Aquino (2000). "The Fall of the House of AHERF: The Allegany Bankruptcy," Health Affairs 19(1):7-41.

Burns, Lawton R., Amit Shah, and Frank A. Sloan (2001). "The Impact of Governance Changes on Strategy: Results from a Study of Hospital Ownership Conversions," University of Pennsylvania.

Conover, Christopher J., Michael E. Ezell, and Frank A. Sloan (2001) . “Understanding Hospital Conversions," unpublished. Duke University.

Conover, Christopher J., and Frank A. Sloan (2001). "Rates of Return from Hospital Conversions," unpublished. Duke University.

Cutler, David M., and Jill R. Horwitz (2000). “Converting Hospitals from Not-for-Profit to For-Profit Status," in David M. Cutler, ed., The Changing Hospital Industry: Comparing Not-for-Profit and For-Profit Institutions. Chicago, IL: University of Chicago Press, 45-79.

Desai, Kamal R., Carol VanDeusen Lukas, and Gary J. Young (2000). "Public Hospitals: Privatization and Uncompensated Care," Health Affairs 19(2):167-172.

Duggan, Mark G. (2000a) . "Hospital Market Structure and the Behavior of Not-for-Profit Hospitals: Evidence from Responses to California's Disproportionate Share Program," NBER Working Paper 7966.

Duggan, Mark G. (2000b). "Hospital Ownership and Public Medical Spending," Quarterly Journal of Economics, 115(4):1343-1373.

Eldenburg, Leslie, Benjamin E. Hermalin, Michael S. Weisbach, and Marta Wosinska (2001). "Hospital Governance, Performance Objectives, and Organizational Form," NBER Working Paper 8201. 
Hart, Oliver, Andrei Shleifer, and Robert W. Vishny (1997). "The Proper Scope of Government: Theory and an Application to Prisons," Quarterly Journal of Economics 112(4):1127-1162.

Kessler, Daniel P., and Mark B. McClellan (2000). "Is Competition Socially Wasteful?" Quarterly Journal of Economics, 115(2):577-615.

Lakdawalla, Darius, and Tomas Philipson (1999). “The Nonprofit Sector and Industry Performance," mimeo, University of Chicago.

Legnini, M. W., L. E. Rosenberg, M. J. Perry, and N. J. Robertson (2000). “Where Does Performance Measurement Go from Here?" Health Affairs 19(3):173-177.

McClellan, Mark, and Douglas Staiger (2000). “Comparing Hospital Quality at For-Profit and Not-for-Profit Hospitals," in David M. Cutler, ed., The Changing Hospital Industry: Comparing Not-for-Profit and For-Profit Institutions. Chicago, IL: University of Chicago Press, 93-112.

Needleman, J., D. J. Chollet, and J. Lamphere (1997). “Hospital Conversion Trends," Health Affairs 16(2):187-195.

Norton, Edward C., and Douglas O. Staiger (1994). "How Hospital Ownership Affects Access to Care for the Uninsured," Rand Journal of Economics 25(1):171-185.

Picone, Gabriel, Shin-Yi Chou, and Frank Sloan (forthcoming). "Are For-Profit Conversions Harmful to Patients and to Medicare?" Rand Journal of Economics.

Robinson, James G. (2000). "Capital Finance and Ownership Conversions in Health Care," Health Affairs (19)1:56-71.

Silverman, Elaine, and Jonathan Skinner (2001). "Are For-Profit Hospitals Really Different? Medicare Upcoding and Market Structure," NBER Working Paper 8133.

Sloan, Frank A. (2000). "Not-for-Profit Ownership and Hospital Behavior," in A. J. Culyer and J. P. Newhouse, eds., Handbook of Health Economics, vol. 1B. Amsterdam: Elsevier, 1141-1174.

Sloan, Frank A., Donald H. Taylor, and Christopher J. Conover (2000). "Hospital Conversions: Is the Purchase Price Too Low?" in David M. Cutler, ed., The Changing Hospital Industry: Comparing Not-for-Profit and For-Profit Institutions. Chicago, IL: University of Chicago Press, 13-44.

Thorpe, Kenneth E., Curtis S. Florence, and Eric E. Seiber (2000). "Hospital Conversions, Margins, and the Provision of Uncompensated Care," Health Affairs 19(6):187-195.

Wolfram, Catherine (2000). "Comment on Chapters 3 and 4: McClellan and Staiger," in David M. Cutler, ed., The Changing Hospital Industry: Comparing Not-for-Profit and For-Profit Institutions. Chicago, IL: University of Chicago Press, 155-158. 
Copyright $\odot 2002$ EBSCO Publishing 